\begin{tabular}{|c|c|c|c|c|c|}
\hline MUNIBE Antropologia-Arkeologia & $n^{\circ} 68$ & $327-351$ & DONOSTIA & 2017 & ISSN 1132-2217 • elSSN 2172-4555 \\
\hline
\end{tabular}

\title{
Busqueda, exhumación e identificación de represaliados de la Guerra Civil enterrados en el cementerio viejo de Palencia: el proyecto de la Carcavilla
}

\author{
Search, exhumation and identification of victims of the Spanish Civil War \\ buried in the old cemetery of Palencia: the Carcavilla project
}

PALABRAS CLAVES: Antropología Forense, Arqueología forense, Identificación, ADN, Cementerio, Archivos.

GAKO-HITZAK: auzitegi-antropologia, auzitegi-arkeologia, identifikazioa, DNA, hilerria, artxibategiak.

KEY WORDS: Forensic Anthropology, Forensic archaeology, Identification, DNA, Cemetery, Archives.

\section{Almudena GARCÍA-RUBIO RUIZ(1,2) y Luis RíOS FRUTOS ${ }^{(1,3)}$}

\section{RESUMEN}

Entre el año 2008 y 2013 se desarrolló el proyecto de exhumación e identificación de víctimas de la represión franquista en el Cementerio Viejo de Palencia, hoy parque de La Carcavilla. Se trataba de un caso complejo debido al tiempo transcurrido desde que ocurrieron los hechos, al elevado número de víctimas buscadas y a la falta de referencias espaciales tras la conversión del Cementerio Viejo en parque de recreo. El resultado fue la exhumación de 108 represaliados de los cuales 57 fueron identificados. La identificación de los restos, objetivo de la intervención, fue posible debido a un enfoque multidisciplinar basado en el cruce de información procedente de fuentes documentales, arqueológicas, osteológicas y genéticas. La reconstrucción de los eventos alrededor de la muerte durante la búsqueda y recuperación de los restos óseos, basada en la interpretación arqueológica y los datos de archivo, el análisis in situ de los mismos en el contexto en el que se encontraron y su posterior estudio en laboratorio, y finalmente el estudio genético, constituye un ejemplo práctico del crecimiento e intersección de la antropología forense con otras disciplinas.

\section{LABURPENA}

2008 eta 2013 artean, Palentziako Hilerri Zaharrean (gaur egun, La Carcavilla parkea) errepresio frankistako biktimak hobitik ateratzeko eta identifikatzeko proiektua garatu zen. Kasu konplexua zen hainbat faktore dela eta: gertaera haietatik igaro den denbora, bilatutako biktimen kopuru handia eta Hilerri Zaharra aisialdirako parke bihurtu ondoren ez zegoelako espazio mailako erreferentziarik. Azkenean, 108 errepresaliatu hobitik ateratzea lortu zuten, eta haietatik 57 identifikatu. Esku-hartze haren helburua hondakin haiek identifikatzea zen eta era askotako iturrietatik iritsitako informazioa partekatzean oinarritutako diziplina anitzeko ikuspegiari esker egin zen: iturri dokumentalak, arkeologikoak, osteologikoak eta genetikoak. Hezur-hondakinak bilatzeko eta berreskuratzeko garaian heriotzaren inguruko gertakizunak berreraikitzea auzitegi-antropologia beste diziplina batuekin elkartzearen eta hazkundea lortzearen adibide praktikoa da. Hori guztia interpretazio arkeologikoan eta artxibategiko datuetan, horiek topatu ziren testuinguruan in situ aztertzean eta ondoren laborategian aztertzean eta, amaitzeko, azterketa genetikoan oinarritzen da.

\section{ABSTRACT}

Since 2000, exhumations of mass graves from the civil war period, have been carried out in Spain with archaeological methodology, as well as identification of exhumed remains, which can be included within the framework of anthropological-forensic investigations of systematic human rights violations.

In the province of Palencia, between July 1936 and 1945, a total of 1,322 people were victims of Francoist repression. 24\% of the victims were buried in mass graves in a specific area of the Old Cemetery in the city of Palencia. According to information from the Cemetery Registry Book, the victims formed 57 synchronic groups of burial.

As a request of the relatives, between 2008 and 2013, the project of exhumation and identification of victims of the Francoist repression was developed in the Old Cemetery of Palencia, currently the park of La Carcavilla. It was a complex case due to the time elapsed since the events occurred, the high number of victims searched and the lack of geographical references after the conversion of the Old Cemetery into a recreational park.

The result of the archaeological field work was the exhumation of 108 victims. Out of the 57 synchronic burial groups searched, only 12 were recovered completely. From the in situ findings, the groups were classified in complete groups, partial groups and missing groups. The process of identification of the victims exhumed in Carcavilla was based on the hypothesis of closed groups. In this paper we summarize the identification process in the Carcavilla through the description of a case of each of the three types of groups.

The identification of the human remains, the main objective of the intervention, was possible due to a multidisciplinary approach based on the corroboration of independent information from testimonies, archives, archaeology, osteology and genetics. Finally, the total result was that 57 victims were identified.

\footnotetext{
(1) Departamento Antropología Física, Sociedad de Ciencias Aranzadi, Zorroagagaina 11, 20014 Donostia, Gipuzkoa. agarciarubio@aranzadi.eus.

(2) Comisión Docente de Antropología Física, Departamento Biología, Universidad Autónoma de Madrid, Darwin 2, 28049 Madrid.

(3) Departamento de Paleobiología, Museo Nacional de Ciencias Naturales (MNCN-CSIC), José Gutiérrez Abascal 2, 28006 Madrid.
} 
This study illustrates the necessity of a joint assessment of information coming from several sources (testimonies, files, archaeology, osteology, genetics), and thus of a multidisciplinary research in the cases of systematic human rights violations. Besides the identification of the remains, the research also made possible the reconstruction of other events related to the cemetery dynamics which had affected the state of preservation of the remains and brought additional information concerning the physical and symbolic status of the victims within the cemetery. The reconstruction of the events around the time of death during the search and recovery of the remains, based on archaeological interpretation and archival data, the in situ analysis of the remains in the context in which they were found and its posterior laboratory study, and finally the genetic study, constitute a practical example of the development and intersection of forensic anthropology with other disciplines.

\section{INTRODUCCIÓN}

Desde el año 2000 se están realizando en España exhumaciones de fosas comunes del periodo de la guerra civil con metodología arqueológica, así como identificación de los restos exhumados, que se pueden englobar dentro del marco de las investigaciones antropológico-forenses de graves violaciones de derechos humanos (ETXEBERRÍA et al. 2012). La exhumación en el año 2000 de los restos de 13 represaliados en una fosa común de la localidad leonesa de Priaranza del Bierzo (SILVA, 2006), inauguró esta última etapa de exhumaciones relativas al periodo de la guerra civil española (FERRÁNDIZ, 2014), y la participación durante la excavación y proceso de identificación de arqueólogos, antropólogos físicos, médicos forenses y genetistas, sentó las bases metodológicas para las posteriores investigaciones antropológico forenses de este periodo reciente de la historia española (PRADA et al. 2003). Esta metodología de trabajo en la investigación de graves violaciones de derechos humanos se materializó durante una década en la intervención de diversos equipos multidisciplinares en diferentes comunidades autónomas (ETXEBERRÍA et al. 2012; GARCÍA-RUBIO e IGLESIAS, 2014; GUIJO et al. 2013; HERRASTI et al. 2012; MALGOSA et al. 2010; MEZQUIDA, 2017; MUÑOZ ENCINAR et al. 2013; POLO et al. 2010; RíOS et al. 2010; 2012), formalizándose a efectos administrativos en diversos protocolos de actuación a nivel autonómico y nacional nutridos de esta experiencia (una revisión en ETXEBERRIA, 2012).

Un total de 8000 esqueletos han sido exhumados desde el año 2000 hasta el 2015, y los resultados obtenidos por los mencionados equipos han mostrado que la identificación de los restos exhumados es un objetivo factible, a pesar de las complicaciones resultantes del prácticamente nulo apoyo judicial, y del deficiente (20042012) o inexistente (2000-2004, 2012-actualidad) modelo de actuación administrativa por parte de los sucesivos gobiernos (ver repaso general en RÍOS y ETXEBERRIA, 2016). Durante el periodo de financiación de las exhumaciones del periodo de la guerra civil (2006-2012), se pudieron llevar a cabo proyectos de cierta envergadura, llegando a exhumarse más de 80 esqueletos por proyecto, en algunos casos con más de 50 identificaciones (e.g. cementerio de presos de Valdenoceda, ver RíOS et al. 2009). En este trabajo presentamos el proceso de identificación de las víctimas de la represión franquista enterradas en el Cementerio Viejo de Palencia.

Entre julio de 1936 y 1945 un total de 1.322 personas fueron víctimas de la represión franquista en la pro- vincia de Palencia, con 867 ejecuciones extrajudiciales, 348 ejecuciones tras juicios sumarísimos sin garantías procesales, y 107 muertes en cautiverio (GARCÍA COLMENARES, 2012). Todas las víctimas de juicios sumarísimos, y el $15 \%$ de las víctimas por muerte extra judicial, fueron enterradas en el Cementerio Viejo de la ciudad de Palencia, hoy convertido en el parque de recreo de La Carcavilla. En el año 2008, a petición de distintas agrupaciones de familiares, dio comienzo un proyecto con el objetivo de localizar, exhumar e identificar a las personas represaliadas enterradas en la Carcavilla. El proyecto incluyó una prospección con georradar, dos campañas de excavación, varias fases de investigación archivística, dos fases de estudio osteológico y genético y fue llevado a cabo por un equipo mixto de la Sociedad de Ciencias Aranzadi (SCA) y la Universidad Autónoma de Madrid (UAM), en colaboración con la Asociación para la Recuperación de la Memoria Histórica de Palencia (ARMHP) y con las distintas agrupaciones de familiares solicitantes. El proyecto se extendió hasta el año 2013, cuando se celebró el último homenaje de recuerdo a las víctimas, así como la devolución a sus familias de los restos identificados, objetivo último de la intervención arqueológico forense.

\section{MATERIAL Y MÉTODOS}

Entre julio de 1936 y diciembre de 1942 fueron enterradas en el Cementerio Viejo de Palencia 485 víctimas de la represión franquista. El cementerio fue clausurado en los años cincuenta y en los años ochenta se convirtió en el parque de recreo municipal de la Carcavilla. Desde el año 2006 las agrupaciones de familiares de represaliados enterrados en el parque de la Carcavilla (Agrupación de Familiares de represaliados de Baltanás y Villaviudas, impulsora de la iniciativa, Agrupación de Familiares de represaliados de Dueñas y Monzón y Agrupación de Familiares de represaliados de Aguilar de Campoo, Palencia y provincia) entraron en contacto con el equipo SCA-UAM para elaborar los proyectos de localización, exhumación e identificación de los restos de los represaliados. Entre los años 2008 y 2011, estos proyectos fueron financiados por las convocatorias del Ministerio de la Presidencia destinadas a actividades relacionadas con las víctimas de la guerra civil y el franquismo. El proceso de identificación se extendió desde el año 2008 hasta el 2013, y contó con fases de excavación, investigación de archivo, estudio osteológico y estudio genético. A continuación se describe la metodología seguida en cada una de estas fases de la investigación. 


\subsection{Testimonios}

Con el objetivo de recabar información ante mortem para la identificación de las personas represaliadas, se realizaron dos convocatorias en el Ayuntamiento de Villaviudas (Palencia) en los años 2009 y 2011. Se emplearon fichas de registro que incluían apartados para los datos personales del solicitante y la persona fusilada; para las condiciones del arresto, juicio, fusilamiento, lugar de desaparición y de enterramiento; e información biográfica sobre el desaparecido como el uso de lentes, prótesis, indumentaria habitual, enfermedades, lesiones o condiciones similares sufridas en vida y otros datos significativos de cara a la identificación. Estas convocatorias también sirvieron para la toma de muestras para los análisis genéticos.

\subsection{Información de archivo}

La investigación de archivo fue llevada cabo principalmente por miembros de la ARMHP, así como por los propios familiares y por miembros del equipo SCA-UAM, siendo la autora (AGR) la que centralizó toda la información relativa al cementerio de La Carcavilla. La investigación documental buscaba dos tipos de información: información ante mortem sobre los represaliados e información sobre la localización de los enterramientos.

Para la obtención de información ante mortem se consultaron: Ios archivos civiles de diversas localidades, el Archivo General Militar de Guadalajara y el Archivo Intermedio de la Región Militar Noroeste de El Ferrol. En los archivos civiles se buscaron las partidas de nacimiento y defunción con el objetivo fundamental de averiguar la edad en el momento del fallecimiento. En los expedientes de tropa del Archivo Militar de Guadalajara se registró información sobre la profesión, la estatura y otras características físicas particulares de los varones que hicieron el servicio militar. En el Archivo Militar de El Ferrol pudieron consultarse algunos sumarios judiciales que contenían dos tipos de información relevante según el momento en que fueron realizados. Los sumarios correspondientes a los primeros días tras el levantamiento militar, describen las circunstancias del hallazgo de cadáveres de desconocidos a los que, tras practicarles la autopsia, se les enterró en el cementerio. A partir del 20 de agosto de 1936, los sumarios judiciales corresponden a juicios sumarísimos y por tanto recogen información sobre las circunstancias de la detención, el proceso judicial, las condenas, fusilamientos y enterramiento de las personas detenidas y condenadas a muerte.

El archivo consultado para la obtención de información sobre la localización de los enterramientos dentro del cementerio fue el Archivo Histórico Municipal de Palencia (AHMP) donde se encuentra la documentación relativa al Cementerio Viejo de la ciudad, incluyendo los Libros de Registro del Cementerio (LRC). Los LRC contienen información individual sobre cada persona enterrada en el cementerio, como los datos personales (nombre, apellidos, edad, estado civil), datos de pro- cedencia (naturaleza, domicilio, parroquia), fechas (de fallecimiento, licencia de enterramiento, inhumación), localización del enterramiento en el cementerio (Término, Sección, Fila, número de Sepultura) y observaciones (ej. judicial, con o sin ataúd, etc.). La investigación completa de los LRC y los sumarios judiciales sirvió para la realización del listado de los represaliados enterrados en el Cementerio Viejo. También en el AHMP se encontraron los contratos de arrendamiento de las sepulturas, fundamentales para entender los hallazgos en campo como se explicará más adelante.

\subsection{Excavación arqueológica}

Se planificó la excavación teniendo en cuenta las particularidades del proyecto (excavación en un parque público, presupuesto limitado y calendario de justificación de las subvenciones), y su objetivo último de localización e identificación de los represaliados. La excavación se realizó en dos campañas que respondieron a peticiones sucesivas de distintos grupos de familiares. En la primera, llevada a cabo en 2009, fueron excavados pequeños sectores, orientados a la búsqueda de cinco grupos de fosas y un total de 30 represaliados. En la segunda campaña, en 2011, fue abierta en extensión toda la zona del parque correspondiente al Término $1^{\circ}$ Sección $3^{\mathrm{a}}$ del Cementerio Viejo, con el objetivo de exhumar todas las sepulturas correspondientes a los 278 represaliados que se buscaban. En ambas campañas se procedió a retirar las capas iniciales, correspondientes a la nivelación para el asentamiento del parque, con máquina retroexcavadora. Una vez expuesto, el nivel cementerial fue excavado estratigráficamente con medios manuales. A cada una de las unidades funerarias documentadas se le asignó un número de unidad estratigráfica (UE) y se cumplimentó una ficha con los datos de posición, descripción del enterramiento y del esqueleto, elementos asociados, datos antropológicos y croquis. En los enterramientos múltiples (fosas) se asignó una UE y se cumplimentó una ficha por cada uno de los esqueletos o depósitos secundarios. Además, se realizó el dibujo arqueológico de los enterramientos colectivos. Todas las UUEE fueron registradas mediante fotografías generales y de detalle. En la campaña de 2009 la planimetría fue realizada de forma manual y en la campaña de 2011 mediante estación total, trabajo realizado por Mugarri, Ingeniería Topográfica S.L.

\subsection{Estudio osteológico}

El estudio osteológico de los restos se llevó a cabo en la Comisión Docente de Antropología Física de la UAM. Para la estimación del sexo se evaluaron variables macroscópicas (PHENICE, 1969; BRUZEK, 2002) y métricas (MURAIL et al., 2005) en la pelvis, y se tuvieron en cuenta los caracteres recomendados por BUIKSTRA et al. (1994) para el cráneo. Para la estimación de la edad primero se agrupó a los esqueletos sobre la base de la maduración ósea en adultos jóvenes (maduración ósea activa) y adultos maduros (fusión completa 
de todos los centros de osificación). Posteriormente se asignó un intervalo de edad de muerte. Para los adultos jóvenes se emplearon referencias de maduración ósea (CARDOSO, 2008a, 2008b; CARDOSO y RIOS, 2010; WEB y SUCHEY, 1985; LANGLEY-SHIRLEY y JANTZ, 2010). Para los adultos maduros se emplearon los métodos de la sínfisis púbica (BROOKS y SUCHEY, 1990), la superficie auricular (BUCKBERRY y CHAMBERLAIN, 2002) y el extremo esternal de la $4^{a}$ costilla (ISCAN y LOTH, 1986). Adicionalmente, para seriar los esqueletos, se evaluó el grado de desarrollo de osteofitos en las vértebras (SNODGRASS, 2005), la osificación de los cartílagos laríngeos (GARVIN, 2008), y el grado de desgaste oclusal en la dentición. La estatura se estimó mediante el método matemático con la longitud de fémur y húmero (DE MENDONÇA, 2000), aplicándose también el método anatómico a los esqueletos mejor conservados (RAXTER et al., 2006, 2007). Se estudió la posible presencia de condiciones patológicas y características morfológicas siguiendo los criterios de $\mathrm{KO}$ MAR y LAPHTROP (2006), y se registraron rasgos no métricos (craneal, postcraneal y dental) con el objetivo de detectar posibles grupos familiares (SAUNDERS y POPOVICH, 1978; RíOS et al., 2010).

\subsection{Muestras para el análisis genético}

Para el estudio genético de los restos óseos se seleccionó como muestra dos dientes (preferiblemente caninos y molares de la maxila), que no presentaran ninguna caries ni fractura visible. Respecto a las muestras biológicas de familiares, en total fueron recogidas 115 muestras de saliva para la identificación de 92 represaliados, con el siguiente grado de parentesco: $8,6 \%$ correspondieron a hermanos o hermanas del fallecido; $44 \%$ a hijos/as; $15,6 \%$ a nietos y $31,3 \%$ a sobrinos/as. Estas muestras se analizaron en el laboratorio LABGENETICS (Madrid).

\section{RESULTADOS Y DISCUSIÓN}

\subsection{Testimonios y Archivos}

A lo largo del proyecto se recogió información testimonial sobre 84 represaliados, incluyendo fotografías de 12 de ellos. En la mayoría de los casos y debido al tiempo transcurrido desde los hechos, los familiares no pudieron ofrecer información relevante de cara a la identificación. Se consideró que solamente nueve tes- timonios ofrecían información potencialmente relevante para la identificación equivalente a una característica morfológica, por ejemplo, un accidente laboral que produjo una fractura de brazo o la existencia de un diente de oro. Respecto a la investigación documental sobre la información ante mortem, en la Tabla I se muestra el número de documentos encontrado en cada archivo y la información obtenida.

Respecto a la información sobre la localización de los enterramientos, la investigación completa de los LRC y los sumarios judiciales resultó en un número total de 485 represaliados y enterrados en el Cementerio Viejo entre julio de 1936 y diciembre de 1942 (GARCÍA COLMENARES, 2012). La mayoría de ellos (310) fueron enterrados en la misma zona del cementerio, el Término $1^{\circ}$ Sección $3^{a}$, distribuidos en 139 sepulturas repartidas en nueve filas, en enterramientos individuales (48), dobles (35), triples (35), cuádruples (19) y quíntuples (2), distribuidos entre los enterramientos ordinarios, tal y como se muestra en la Tabla II.

El "Reglamento para el Santo Cementerio de la ciudad de Palencia" de 1884, establece que el capellán y el sepulturero tendrán un "plano comprensivo de la división del Cementerio, con la numeración de sus sepulturas", sin embargo, ese plano no se encontró. El arquitecto Federico Lozano Ginel, pudo realizar un plano virtual

\begin{tabular}{|l|c|c|c|c|}
\hline \multicolumn{5}{|c|}{ ARCHIVOS } \\
\hline \multirow{2}{*}{ DOCUMENTOS } & \multicolumn{2}{|c|}{ Civil } & $\begin{array}{c}\text { Militar } \\
\text { Guadalajara }\end{array}$ & $\begin{array}{c}\text { Militar } \\
\text { Ferrol }\end{array}$ \\
\cline { 2 - 6 } & $\begin{array}{c}\text { Acta } \\
\text { nacimiento }\end{array}$ & $\begin{array}{c}\text { Acta } \\
\text { defunción }\end{array}$ & $\begin{array}{c}\text { Expediente } \\
\text { militar }\end{array}$ & $\begin{array}{c}\text { Sumario } \\
\text { judicial }\end{array}$ \\
\cline { 2 - 6 } & 203 & 223 & 52 & $23^{\mathrm{A}}$ \\
\hline Edad & \multicolumn{2}{|c|}{239} & - & - \\
\hline Talla & - & - & 53 & - \\
\hline $\begin{array}{l}\text { Señas } \\
\text { Particulares }\end{array}$ & - & - & 6 & - \\
\hline Parentesco & 15 & - & - & - \\
\hline Profesión & - & - & - & 74 \\
\hline Autopsia & - & - & - & $46^{\mathrm{B}}$ \\
\hline Causa de muerte & - & 223 & - & - \\
\hline
\end{tabular}

Tabla 1: A: Cada sumario judicial recoge información de un número variable de personas. B: Sobre la utilidad de los signos de autopsia en la identificación de restos óseos procedentes de las fosas de la guerra civil, incluida la Carcavilla, ver RíOS et al. 2014 / A: Each court record has information about a variable number of people. B: On the utility of autopsy signs in the identification of skeletal remains from civil war graves, including Carcavilla, see RíOS et al. 2014

\begin{tabular}{|l|c|c|c|c|c|c|c|c|c|c|}
\hline TIPO DE FOSA & Fila 1 & Fila 2 & Fila 3 & Fila 4 & Fila 5 & Fila 6 & Fila 7 & Fila 8 & Fila 9 & TOTAL \\
\hline Individual & 4 & 15 & 12 & 7 & 3 & 1 & 2 & 3 & 1 & 48 \\
\hline Doble & - & 11 & 8 & 13 & 2 & - & - & - & 1 & 35 \\
\hline Triple & - & - & 13 & 3 & 2 & 2 & 11 & 1 & 3 & 35 \\
\hline Cuádruple & - & - & - & 5 & 3 & 1 & 2 & 1 & 7 & 19 \\
\hline Quíntuple & - & - & - & 1 & - & - & - & - & 1 & 2 \\
\hline
\end{tabular}

Tabla 2: Distribución de las fosas de represaliados en el Término $1^{1}$ Sección $3^{\text {a }}$ del cementerio. / Distribution of victim's graves in $1^{\text {st }}$ Quadrant, $3^{\text {rd }}$ Section of cemetery. 


\subsection{Excavación arqueológica y exhumación}

Antes de la excavación arqueológica hubo dos intervenciones encaminadas a la localización de las fosas: una prospección con georradar cuyos resultados fueron poco concluyentes (AVIAL, 2008), y unos sondeos con máquina excavadora, que confirmaron la presencia de enterramientos bajo el parque (JIMÉNEZ, 2009). La excavación se realizó en dos campañas. En ser consultada en GARCÍA-RUBIO et al. 2016.

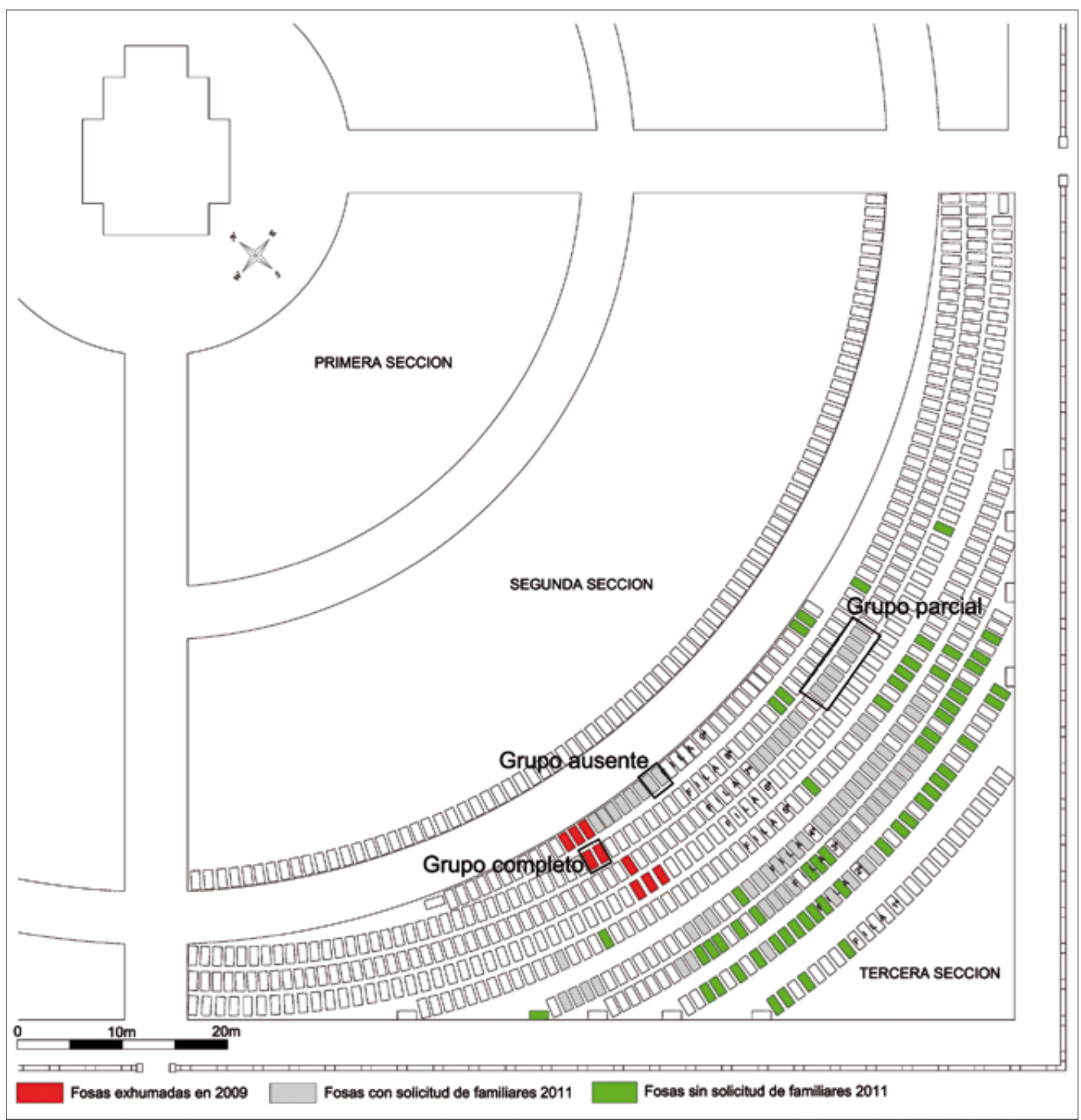

Fig.1. Plano virtual del Término $1^{\circ}$ Sección $3^{a}$ del Cementerio Viejo de Palencia. Se señalan en rojo las fosas exhumadas en la campaña de 2009 , en gris las fosas buscadas en la campaña de 2011 por petición de familiares y en verde las fosas buscadas en la campaña de 2011 por petición del Ayuntamiento de Palencia. También se indica la posición de los grupos que servirán de ejemplo en el artículo. / Virtual map of $1^{\text {st }}$ quadrant, $3^{\text {rd }}$ section of Old Cemetery from Palencia. Red colour: graves excavated in 2009. Grey colour: graves searched for request of relatives in 2011. Green colour: graves searched for request of Municipality of Palencia in 2011. The position of the groups that will be explain in this paper are signaled as well. 
la primera, llevada a cabo en 2009, fueron excavados pequeños sectores, orientados a la búsqueda de cinco grupos de fosas que representaban cinco momentos represivos: 30 de julio, 1 de septiembre y 12 de diciembre de 1936, y 18 de enero y 10 de marzo de 1937. Según los LRC, los enterramientos de estas personas estaban distribuidos en once fosas de las filas 2, 4, 6, 7 y 8 del Término $1^{\circ}$ Sección $3^{\mathrm{a}}$. Como resultado de la campaña fueron exhumados 32 cuerpos procedentes de nueve fosas de los cuales se obtuvieron 19 identificaciones genéticas y dos osteológicas al final del proceso (GARCÍA-RUBIO et al. 2009). Sin embargo, las fosas de las filas 2 y 4 no pudieron ser localizadas ya que la ubicación de las filas 1 a 5, así como la distribución de las sepulturas en ellas, eran imprecisas, por existir menos referencias, como advertía el propio Lozano en la elaboración del plano virtual (LOZANO, 2009).

En la segunda campaña, en 2011, fue abierta en extensión la zona del parque correspondiente al Término $1^{\circ}$ Sección $3^{\mathrm{a}}$ del Cementerio Viejo con el objetivo de exhumar todas las sepulturas correspondientes a represaliados. Esto respondía a una condición puesta por el Ayuntamiento de Palencia para permitir la excavación. Aunque en esta segunda fase había 80 peticiones de familiares, el Ayuntamiento solicitó que se buscaran y exhumaran los 278 represaliados que permanecían supuestamente enterrados en esa zona del cementerio y así evitar futuras intervenciones arqueológicas en la zona de juegos infantiles del parque municipal (Figura 1).

En total en las dos campañas fueron documentadas 348 unidades funerarias, de las cuales 209 correspondían a enterramientos ordinarios (en azul en la Figura 2) y 139 correspondían a fosas, es decir, enterramientos vinculados a la represión franquista (en verde en la Figura 2). Sin embargo, sólo 42 fosas permanecían intactas (en verde y rayadas en la Figura 2). Las demás habían sufrido alteraciones posteriores. La mayoría de ellas eran reutilizaciones practicadas en los años cuarenta, mientras el cementerio aún estuvo en uso. En otros casos (siete) las alteraciones fueron consecuencia de las obras de acondicionamiento del parque en los años ochenta. Respecto a las reutilizaciones, los enterramientos consecuencia de la represión siguieron la misma dinámica que el resto de enterramientos en el cementerio. A los cinco años del sepelio era necesario pagar unas tasas de arrendamiento para conservar la sepultura por otros cinco años, en caso contrario, los restos óseos eran trasladados al osario (GARCíA-RUBIO et al. 2016). Los hallazgos inesperados en la segunda campaña de excavación llevaron a ampliar la investigación en el AHMP donde fueron encontrados 44 contratos de arrendamientos correspondientes a fosas de represaliados, que no se conocían hasta ese momento (ver más adelante).

\subsection{Estudio osteológico e identificación}

De los 110 esqueletos exhumados pertenecientes a represaliados, se pudo estimar el sexo de todos los esqueletos, siendo todos masculinos menos uno (UE 10.211), lo cual coincidía con los datos ante mortem sobre las personas enterradas en el cementerio. La edad pudo ser estimada en 104 casos, con 49 casos con signos de maduración activa, de los cuales 19 serían menores de 25 años y 30 menores de 32 años. Entre los esqueletos con maduración completa, 17 se agruparían en torno a una media de 25 años de edad, 28 se agrupan en una media de 35 años de edad y 9 en una media de 45 años de edad. La estatura pudo ser estimada en 102 casos, presentando una media de 161,9 $\mathrm{cm}$ y unos valores que oscilaban entre 154 y $177,8 \mathrm{~cm}$ de altura.

A la hora de plantear las identificaciones se partió de un universo de identificación, definido como aquel compuesto por aquellas personas que pudieron haber terminado como los restos del caso estudiado, inicialmente conocido a partir de la información de testimonios y archivos (Tabla I). A partir de esta base se trabajó con hipótesis de grupos cerrados, tal y como se han definido previamente (BARAYBAR, 2008; RíOS et al., 2010, RíOS, 2012). En esta lógica, si la información sobre el grupo de personas que se buscan (número de personas, localización del enterramiento, sexo y edad de los fallecidos) resulta compatible con la información del grupo de esqueletos recuperados (localización de la fosa, número de esqueletos, estimaciones de sexo, edad y otras características físicas), se confirma de manera tentativa la presencia de un grupo cerrado, simplificando la identificación como si se tratara de un caso de accidente de avión en el que se dispone de un listado completo de víctimas (VALLEJO y ALONSO 2009; BARBERIA-MARCALAIN et al. 2009; OLADAPO et al. 2015).

En el caso de la Carcavilla, el 75\% de las víctimas fueron fusiladas tras ser condenadas en juicio sumarísimo. A través de los sumarios judiciales y del LRC, sabemos que los represaliados eran llevados al cementerio tras la ejecución, por lo que forman grupos sincrónicos de enterramiento. Por ejemplo, el grupo de ocho hombres de Aguilar de Campoo fusilado el 20 de agosto de 1936, fue enterrado en cuatro fosas de la fila 3 , pero forma un solo conjunto de inhumación, grupo sincrónico de enterramiento o grupo cerrado. La hipótesis de grupo cerrado se sustenta en el cruce de información procedente de diversas fuentes. Por un lado, la información ante mortem sobre las personas que se buscan (sexo, edad, estatura, características físicas), proporcionada por los familiares y testigos o por los documentos consultados (Tabla I). Por otro lado, información sobre la potencial localización del enterramiento y de las personas presuntamente allí enterradas, en el caso de la Carcavilla información obtenida a partir de los LRC. Ambos tipos de información se contrasta con la obtenida en la excavación arqueológica (ubicación de la fosa, número de esqueletos recuperados, objetos personales, proyectiles y otras evidencias asociadas), y en el estudio osteológico (perfil biológico estimado, 
características físicas, variantes anatómicas etc.). Si el cruce de información es compatible sobre el grupo y sobre los individuos, se realizan propuestas de identificación que orienten los análisis genéticos, tal y como se resume en la Figura 17, al final del artículo.

Según el LRC, en el Término $1^{\circ}$ Sección $3^{a}$ fueron enterradas 310 personas fruto de la represión, forman- do 57 grupos sincrónicos. Aunque usamos la palabra "grupo" hay 14 casos en los que se trata de una sola persona, siendo el resto grupos cuyo número oscila entre dos y 30 personas, que pueden estar enterrados en una sola sepultura o repartidos hasta en 14 fosas (Tabla II). A partir del cruce de esta información documental y de la información arqueológica, ya en campo los hallazgos se clasificaron en tres tipos de grupos (Tabla III):

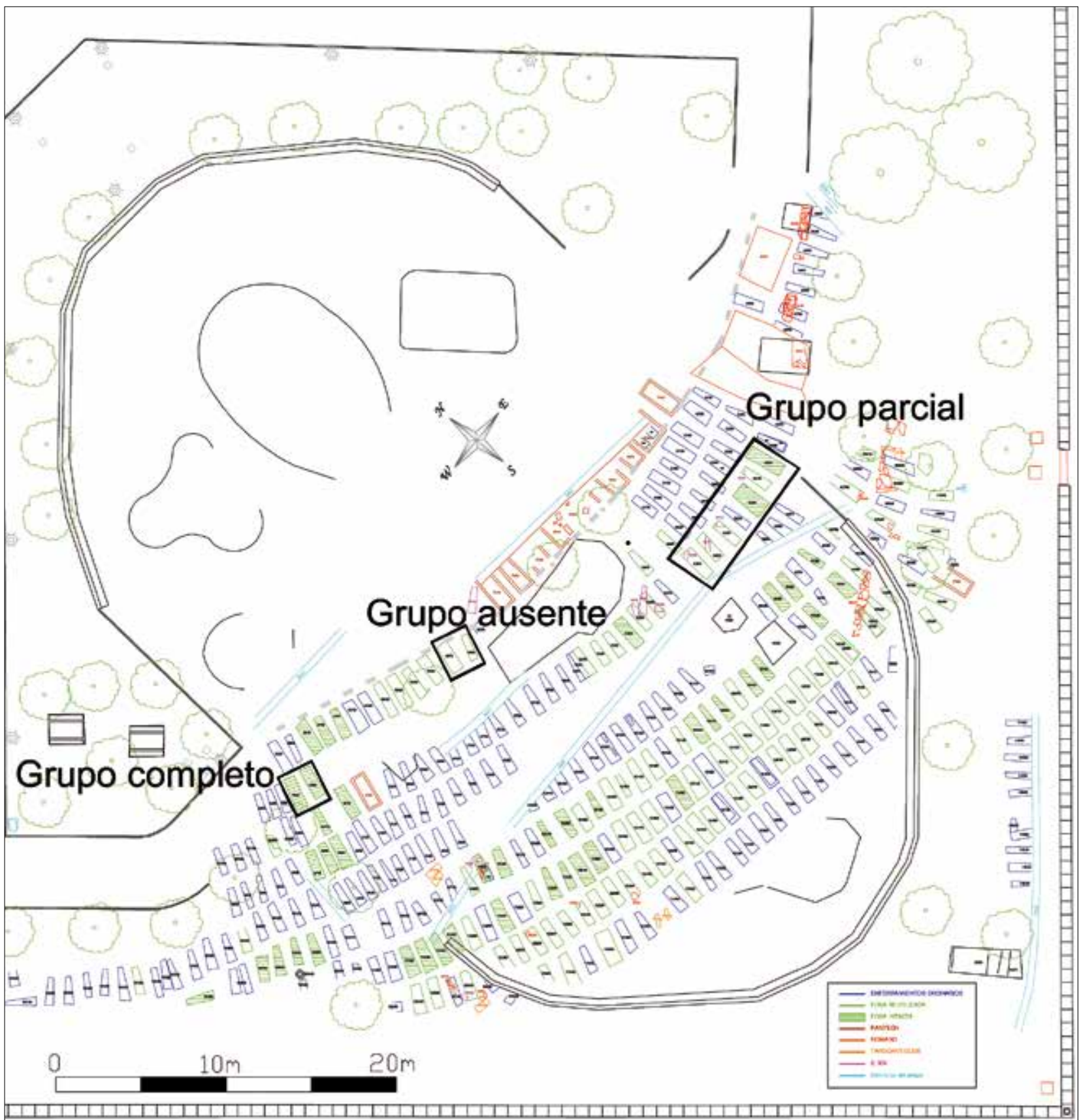

Fig.2. Planimetría del área excavada correspondiente al Término $1^{\circ}$ Sección $3^{a}$ del Cementerio Viejo de Palencia. Se señalan en azul las unidades funerarias correspondientes a enterramientos ordinarios y en verde las correspondientes a fosas fruto de la represión. Las verdes rayadas son aquellas recuperadas íntegramente. También se indica la posición de los grupos que servirán de ejemplo en el artículo. / Planimetry of the excavated area corresponding to the $1^{\text {st }}$ quadrant, $3^{\text {rd }}$ section of Old Cemetery from Palencia. Those corresponding to ordinary burials are indicated in blue. Those corresponding to civil war burials are indicated in green.The striped greens are those wholly recovered. The position of the groups that will be explain in this paper are signaled as well. 


\begin{tabular}{|c|c|c|c|c|}
\hline \multicolumn{2}{|l|}{$\begin{array}{l}\text { SEGÚN } \\
\text { DOCUMENTACIÓN }\end{array}$} & \multicolumn{3}{|c|}{$\begin{array}{l}\text { RESULTADO EXCAVACIÓN } \\
\text { ARQUEOLÓGICA }\end{array}$} \\
\hline Represaliados & Grupos & $\begin{array}{c}\text { Grupos } \\
\text { completos }\end{array}$ & $\begin{array}{c}\text { Grupos } \\
\text { parciales }\end{array}$ & $\begin{array}{c}\text { Grupos } \\
\text { ausentes }\end{array}$ \\
\hline 310 & 57 & 12 & 10 & 35 \\
\hline
\end{tabular}

Tabla 3: Izquierda. Número de grupos sincrónicos de enterramientos según la documentación. Derecha. Número de grupos sincrónicos recuperados en la excavación de forma completa, parcial o no recuperados (ausente). / Left. Number of synchronic burial groups according to the documentation. Right. Number of synchronic burial groups according to the excavation. We found complete groups, partial groups and absent groups (those that were not found).

- Grupos completos: aquellos en los existía correspondencia entre el número de personas buscadas y el número de esqueletos exhumados. Se recuperaron 12 grupos completos.

- Grupos parciales: solo se pudo recuperar un número parcial de esqueletos respecto del total de personas que fueron asesinadas y enterradas ese mismo día. Las posibilidades de identificación en estos grupos son muy variables, principalmente en función del número de esqueletos recuperados. Por ejemplo, del grupo de represaliados el 8 de enero de 1937, formado por 19 hombres de Dueñas, solo se recuperaron completos tres esqueletos. En estos casos, aunque haya abundante información documental y familiares para el cotejo genético, las opciones de identificación se ven lógicamente limitadas. Se recuperaron 10 grupos parciales.

- Grupos ausentes: aquellos en los que todas las fosas estaban reutilizadas y no fue posible recuperar ningún esqueleto completo. Sin embargo, se dieron algunos ejemplos en los que se recuperaron algunos huesos que permitieron inferir que las personas que se buscaban estuvieron allí enterradas. A fecha de hoy no se ha podido realizar ninguna identificación en un grupo ausente a partir del estudio de los fragmentos óseos. Hubo 35 grupos ausentes.

A continuación resumimos el proceso de identificación en la Carcavilla a través de la descripción de un caso de cada uno de los tres tipos de grupos.

\section{GRUPO COMPLETO}

La investigación a partir de los testimonios y los archivos indicaba que siete hombres de Baltanás fueron fusilados y enterrados en el Cementerio Viejo de Palencia el 10 de marzo de 1937. Estos hombres eran Domingo Adrián Vega, Julián Diago Espina, Máximo Calleja Espina, Segundo Calleja Calvo, Antonio Adrián Vega, Jesús Adrián Vega y Terencio Cabestrero Ortega. La información ante mortem disponible, procedente de varios archivos civiles y militares, se resume en la Tabla IV. De cara a la identificación, cabe destacar que entre los fusilados hay cuatro menores de 30 años y un grupo de tres hermanos, los hermanos Adrián Vega (AV). Cinco de los represaliados tenían muestra de un familiar para el estudio genético. Según el LRC estas siete personas fueron enterradas en las sepulturas 65 y 66 de la fila 8 del Término $1^{\circ}$ Sección $3^{a}$ formando un enterramiento cuádruple y uno triple.

Estas sepulturas fueron identificadas tentativamente como las UUEE 3.180 y 3.400 , excavadas en la campaña del 2009. La fosa UE 3.180, albergaba en su interior cuatro esqueletos depositados decúbito supino. Los dos primeros en ser depositados en la fosa (3.184 y 3.183), siguen una orientación Norte-Sur. Los dos últimos en ser depositados en la fosa (3.182 y 3.181), están en sentido contrario (Figura 3). La fosa UE 3.400 albergaba en su interior tres esqueletos en decúbito supino, los dos primeros en ser depositados en la fosa (3.402 y 3.403) siguen una orientación Sur-Norte y el último, UE 3.401, fue colocado sobre los anteriores siguiendo la orientación contraria (Figura 3, derecha). En ambas fosas los restos estaban bien conservados (en la UE 3.180 los esqueletos perdieron algunos elementos debido a las obras posteriores del parque), recuperándose elementos de vestimenta como las suelas del calzado, botones y trabillas metálicas, y documentándose la presencia de cal (para un estudio del uso de la cal en la Carcavilla ver SCHOTSMANS et al., 2016). En todos los esqueletos se observó trauma peri mortem (para un estudio de patrones de trauma peri mortem en restos del periodo de la guerra civil, incluyendo la Carcavilla, ver RIOS et al., 2014). En la Tabla V se resumen los hallazgos del estudio osteológico de los restos. To-

\begin{tabular}{|c|c|c|c|c|c|c|}
\hline NOMBRE & DEFUNCION & EDAD & TALLA & OTROS & UBICACIÓN & FAMILIAR \\
\hline DAV & \multirow{7}{*}{ 10/03/1937 } & 27 & - & Dulzainero & \multirow{4}{*}{$\begin{array}{l}\text { Sepultura } 65 \\
\text { Fila } 8\end{array}$} & Hijo \\
\hline JDE & & 29 & 159 & - & & Hijo e hija \\
\hline MCE & & 27 & 161 & Labrador & & - \\
\hline SCC & & 42 & - & Jornalero & & Hijo y nieto \\
\hline AAV & & 40 & - & Dulzainero & \multirow{3}{*}{$\begin{array}{c}\text { Sepultura } 66 \\
\text { Fila } 8\end{array}$} & Hija y sobrino \\
\hline JAV & & 26 & - & Dulzainero & & - \\
\hline TCO & & 40 & - & Industrial & & - \\
\hline
\end{tabular}

Tabla 4: Información ante mortem del grupo enterrado el 10 de marzo de 1937. En naranja se indica el grupo de parentesco, los hermanos AV. / Ante mortem information of burial group of 10 March 1937. Orange colour indicates a kinship group, the siblings AV. 

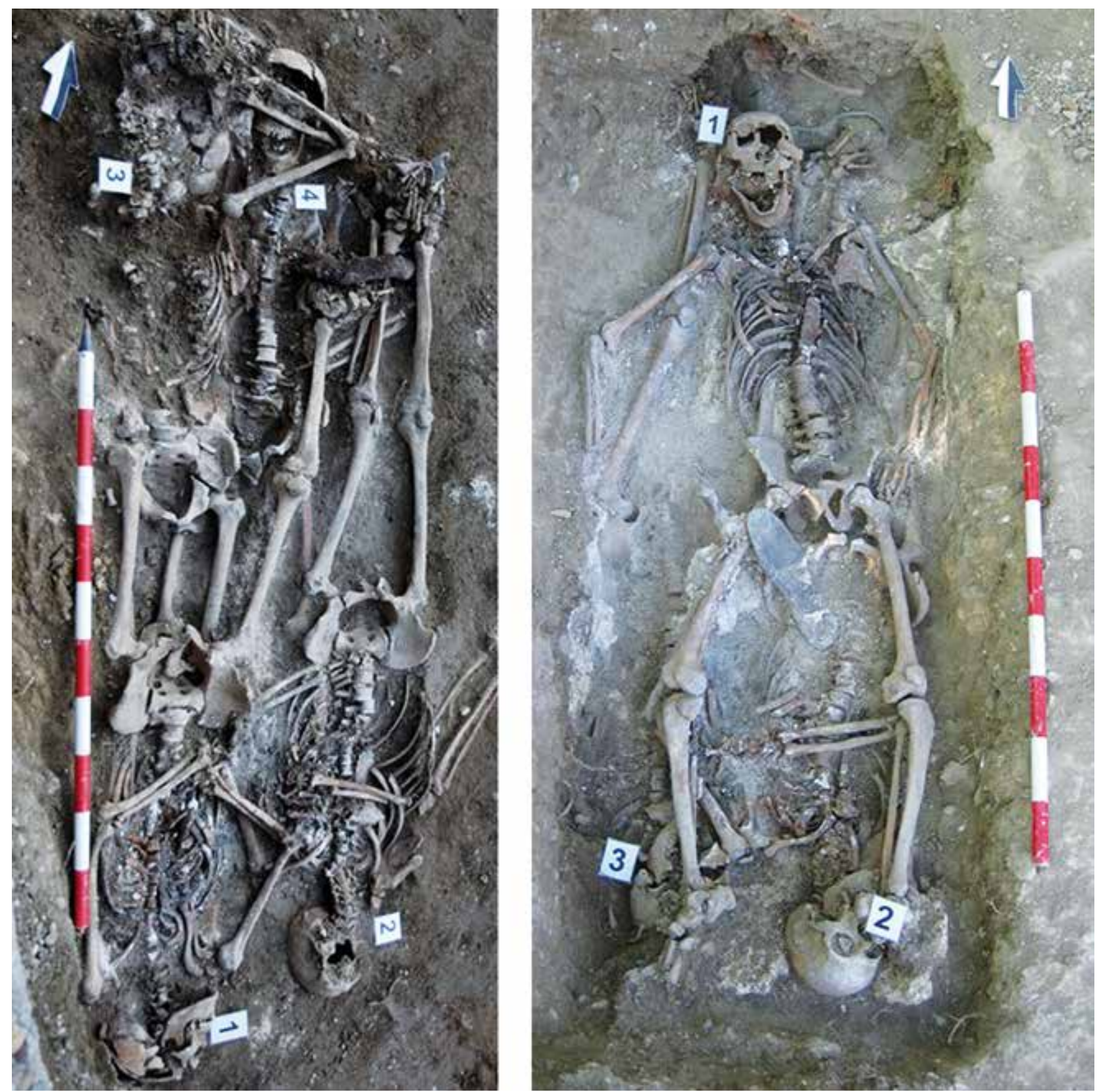

Fig.3. Izquierda. Fosa UE 3.180. Derecha. Fosa UE 3.400. / Left. Grave 3.180. Right. Grave 3.400

\begin{tabular}{|c|c|c|c|c|c|}
\hline \multirow{2}{*}{ UE fosa } & UE esqueleto & SEXO & EDAD & TALLA & OBSERVACIONES \\
\hline \multirow{4}{*}{3.180} & 3.181 & $M$ & $<32^{\mathrm{B}}$ & $1.58 \pm 6.90^{\mathrm{D}}$ & C1 puente dorsal izqdo \\
\cline { 2 - 6 } & 3.182 & $\mathrm{M}$ & $35.2(23-57)^{\mathrm{C}}$ & $165.79^{\mathrm{A}}$ & - \\
\cline { 2 - 6 } & 3.183 & $\mathrm{M}$ & $28.7(21-46)^{\mathrm{C}}$ & $1.58 \pm 6.90^{\mathrm{D}}$ & - \\
\hline \multirow{3}{*}{3.400} & 3.184 & $\mathrm{M}$ & $35.2(23-57)^{\mathrm{C}}$ & $157.50^{\mathrm{A}}$ & C1 puente dorsal bilateral \\
\cline { 2 - 6 } & 3.401 & $\mathrm{M}$ & $35.2(23-57)^{\mathrm{C}}$ & $160.7 \pm 6.96^{\mathrm{D}}$ & C1 puente dorsal bilateral \\
\cline { 2 - 6 } & 3.402 & $\mathrm{M}$ & $45.6(27-66)^{\mathrm{C}}$ & $159.8 \pm 6.96^{\mathrm{D}}$ & - \\
\hline
\end{tabular}

Tabla 5: Resumen estudio osteológico. Sexo masculino. B: estimación de la edad en base a Langley-Shirley y Jantz (2010). C: estimación de la edad en base a Suchey y Brooks (1986). A: estimación de estatura por método anatómico de Raxter (2006). D: estimación de estatura por método matemático de Mendoça (2000). / Osteological findings of the 10 March 1937 group. Male. B: age range from Langley-Shirley y Jantz (2010). C: age range from Suchey y Brooks (1986). A: stature from Raxter (2006). D: stature from Mendoça (2000). 
das las estimaciones de sexo fueron masculinas, con un esqueleto clasificado como adulto joven menor de 32 años, y el resto con una edad media entre los 28 y los 45 años. La estimación de la estatura media osciló entre 157 y $166 \mathrm{~cm}$.

Se concluyó que había compatibilidad entre los datos ante mortem y los datos arqueológicos (localización del enterramiento, número y distribución de los esqueletos), así como entre los datos ante mortem y los datos osteológicos (estimación de sexo y edad), y sabiendo que en el grupo de siete hombres había un grupo de tres hermanos, se prestó especial interés al hecho de que tres de los siete esqueletos presentaban una variante anatómica en el atlas, el arco dorsal (Figura 4), que puede indicar relación de parentesco (ALT, 1997; RíOS et al., 2010). La prevalencia del arco dorsal se sitúa entre el 9\% (arco completo) y el 17\% (completos e incompletos) de media (RíOS et al., 2017), y presenta cierto componente genético (SAUNDERS y POPOVICH, 1978). Las estimaciones de edad de estos tres esqueletos resultaban compatibles con las edades proporcionadas por la información ante mortem de los hermanos fusilados. Sobre la base de la información ante mortem, arqueológica y osteológica se propuso la identificación de los hermanos AV como los esqueletos $3.181,3.184$ y 3.401. La presencia del hijo de uno de los hermanos llevó a proponer en primer lugar el estudio de los Y-STRs de ésta muestra indubitada y de los tres esqueletos presuntamente identificados como los tres hermanos. Se obtuvo una coincidencia entre las cuatro muestras. Posteriormente se realizó el estudio de los STRs del esqueleto 3.181 (osteológicamente el más joven) y la muestra indubitada del hijo de DAV, obteniéndose otra coincidencia. Para la identificación de SCC se tenían las muestras de un hijo y de un nieto, hijo de hijo. Inicialmente se realizó el estudio de los Y-STRs, que mostró la coincidencia de dos esqueletos (3.183 y 3.402) con la muestra indubitada del familiar de SCC. La persona buscada compartía el primer apellido, "Calleja", con otra de las víctimas, pero a los familiares no les constaba que hubiera relación de parentesco entre los fallecidos. Una investigación de las partidas de bautismo del archivo parroquial de Baltanás mostró que ambas víctimas compartían un pariente paterno por vía directa nacido en 1712 (Figura 5). Se realizó por tanto el análisis de STRs, que fue coincidente entre 3.402 y el familiar solicitante. Esto, sumado a la compatibilidad arqueológica y osteológica, permitió identificar a MCE como el esqueleto 3.183. Finalmente, para la identificación de JDE se tenían muestras de un hijo y una hija y el análisis de los STRs resultó en una coincidencia entre la muestra ósea de 3.403 y la indubitada. De esta manera, quedaron identificados con prueba genética seis de los siete esqueletos recuperados. El esqueleto restante, 3.182, podría identificarse tentativamente como TCO. En la Tabla VI se resumen las identificaciones obtenidas.
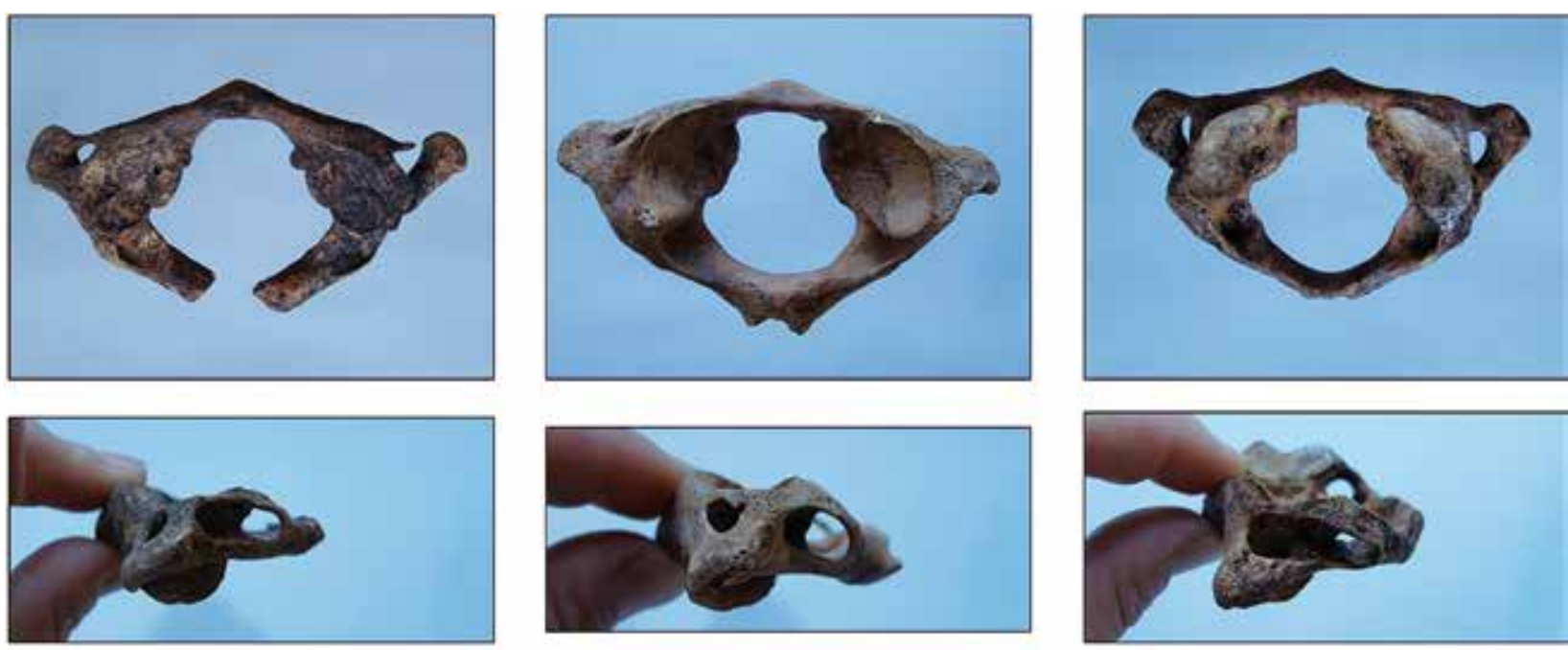

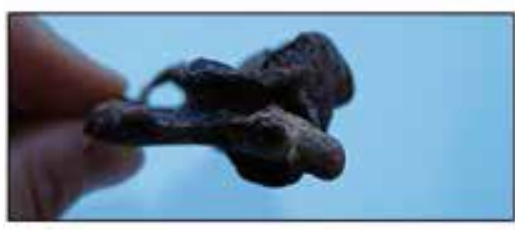

3.181

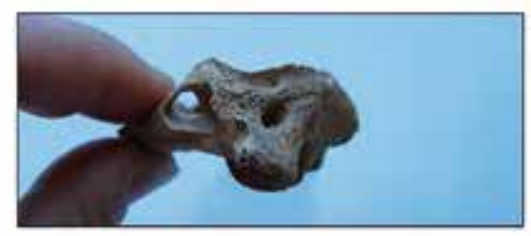

3.184

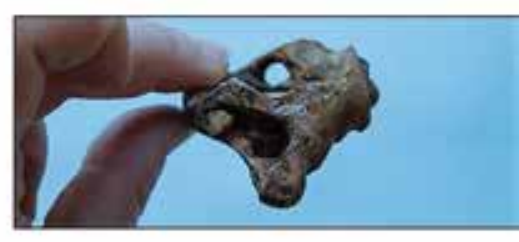

3.401

Fig.4. Norma superior, izquierda y derecha de los atlas de 3.181, 3.184 y 3.401. / From top to bottom, superior, left and right views of atlas from 3.181, 3.184 y 3.401. 


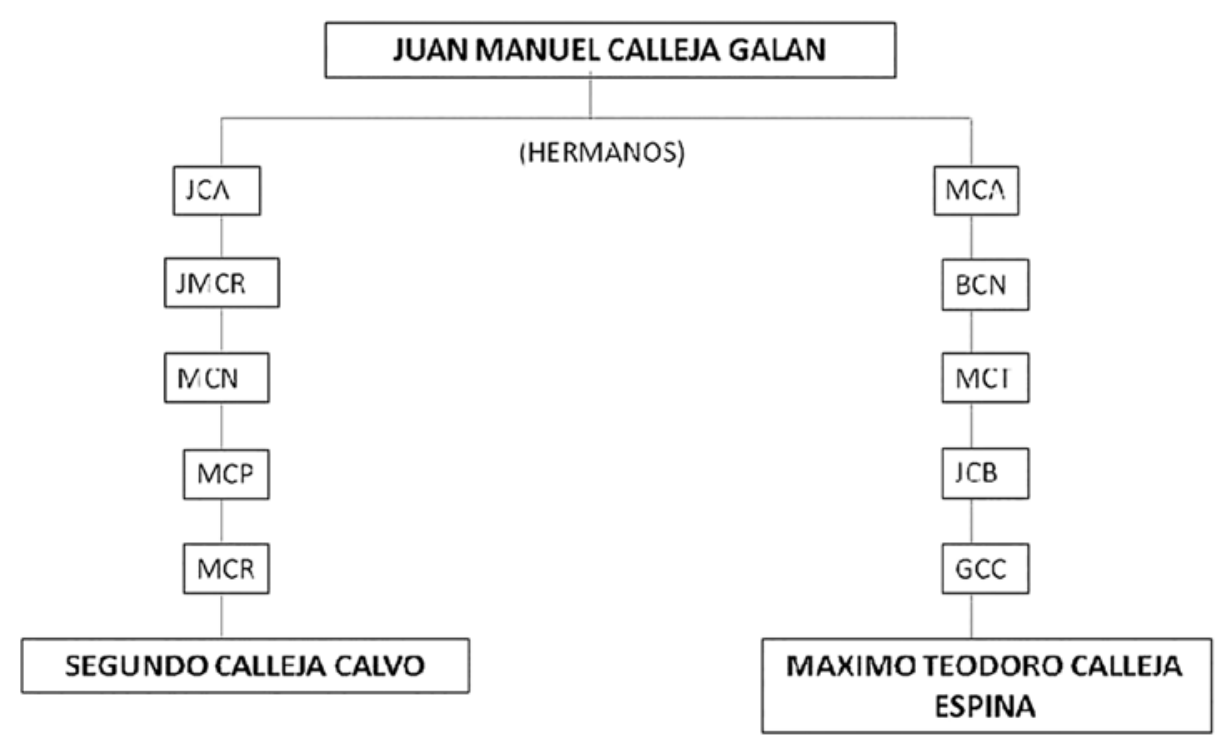

Fig.5. Esquema que refleja el parentesco entre SCC y MCE seis generaciones atrás, según el libro de bautismos del Registro Parroquial de Baltanás. Cortesía de Manolo Monge. / Scheme that shows the kinship between SCC and MCE six generations ago, according to the book of baptisms of the Parish records of Baltanás. By Manolo Monge.

\begin{tabular}{|c|c|c|c|c|c|c|}
\hline SEPULTURA & NOMBRE & EDAD & UE & EDAD & OBSERVACIONES & DNA \\
\hline \multirow{4}{*}{ SEP 65 FILA 8 } & DAV & 27 & 3.181 & $<32$ & C1 puente dorsal izqdo & STRs (21) \\
\cline { 2 - 7 } & JDE & 29 & 3.403 & $35.2(23-57)$ & - & STRS (9) \\
\cline { 2 - 7 } & MCE & 27 & 3.183 & $28.7(21-46)$ & - & Y-STRs (15) \\
\cline { 2 - 7 } & SCC & 42 & 3.402 & $45.6(27-66)$ & - & STRs (15) \\
\hline \multirow{3}{*}{ SEP 66 FILA 8 } & AAV & 40 & 3.184 & $35.2(23-57)$ & C1 puente dorsal bilateral & Y-STRs (10) \\
\cline { 2 - 7 } & JAV & 26 & 3.401 & $35.2(23-57)$ & C1 puente dorsal bilateral & Y-STRs (8) \\
\cline { 2 - 7 } & TCO & 40 & 3.182 & $35.2(23-57)$ & & Osteológica \\
\hline
\end{tabular}

Tabla 6: Resumen de las identificaciones obtenidas en el grupo enterrado el 10 de marzo de 1937. / Summary of the identifications from the group buried the 10 of March of 1937.

El grupo de Baltanás ejemplifica la corroboración de la hipótesis de grupo cerrado, construida sobre la compatibilidad entre los datos de localización de las fosas en el cementerio y los hallazgos arqueológicos, entre los datos ante mortem de las personas buscadas y los resultados osteológicos, y sobre la coincidencia de las pruebas genéticas dirigidas dentro del universo de identificación de la Carcavilla. Tras las identificaciones, es importante observar que no existe correspondencia exacta entre los datos del libro del cementerio y la distribución de los cadáveres en las dos sepulturas (Figura $6)$, es decir, entre la distribución de esqueletos esperada y la observada. Este hecho podría deberse a que el sepulturero desconocía la identidad exacta de los cadáveres que enterraba, y veremos que se repite en otros grupos dificultando el proceso de identificación.

\section{GRUPO PARCIAL}

La investigación a partir de los testimonios y los archivos indicaba que 18 hombres de Dueñas fueron fusilados y enterrados en el Cementerio Viejo de Palencia el 7 de enero de 1937. Estos hombres eran Máxi- mo Alonso Díaz, Gregorio Alonso Díaz, Eulogio Alonso Díaz, Jesús Antolín Álvarez, Bonifacio Barrasa López, Santiago Balbás de la Llana, Félix Camino Bustamante, Gaudencio Fernández Hernández, Félix Galindo Izquierdo, Andrés Galindo López, Adelino Gamazo Rodríguez, Donato García Bravo, Pedro García Delgado, Domingo García Martínez, Hermógenes García Martínez, Emilio García Montoya, David González Gazapo y Pablo Camino Bustamante. La información ante mortem disponible se resume en la Tabla VII. De cara a la identificación, cabe destacar que entre los fusilados hay 13 adultos jóvenes, 10 de ellos menores de 25 años y dos grupos de hermanos: los tres hermanos Alonso Díaz (AD) y los dos hermanos Camino Bustamante (CB). Además, hay familiares de ocho represaliados para el cotejo genético. Según el LRC estas 18 personas fueron enterradas en las sepulturas 40, 41, 42, 44, 45 y 46 de la fila 7 del Término $1^{\circ}$ Sección $3^{a}$ formando seis enterramientos triples.

Estas sepulturas fueron identificadas tentativamente como las UUEE 6.200, 6.210, 6.220, 6.240, $6.250 \mathrm{y}$ 6.260, excavadas en la campaña de 2011. La fosa UE 6.200 , albergaba en su interior tres esqueletos deposi- 


\section{Sepultura 65 Sepultura 66}
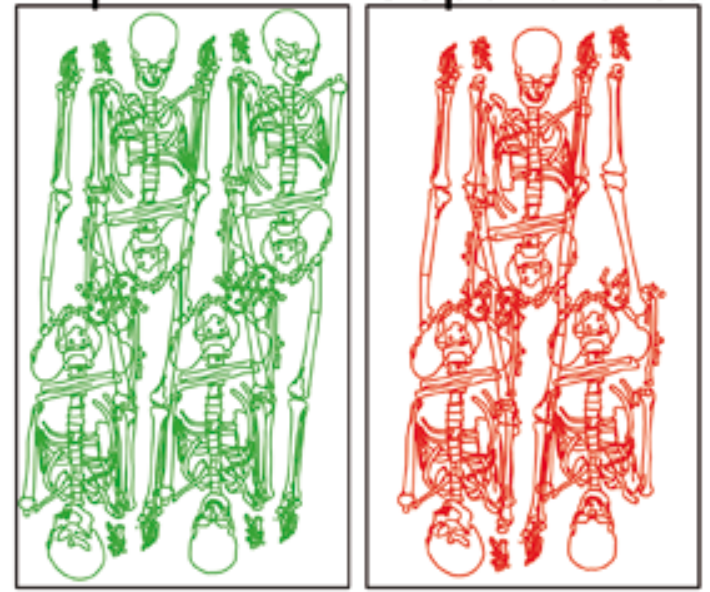

Distribución esperada

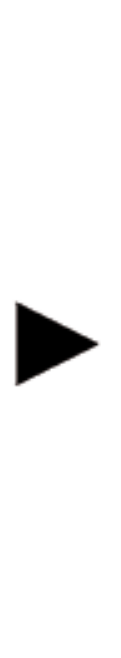

UE 3180

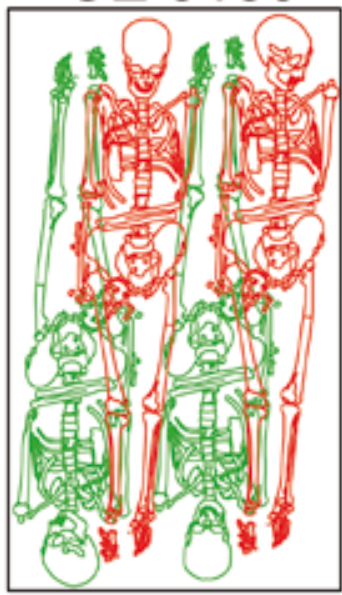

Distribución observada

Fig.6. Izquierda. Representación de la distribución de los cadáveres en las sepulturas 65 y 66 de la fila 8 según el LRC. Derecha. Representación de la distribución real de los esqueletos una vez alcanzadas las identificaciones. / Left. Representation of the distribution of the corpses in graves 65 and 66 of row 8 , according to the Cemetery Record Book (CRB). Right. Representation of the real distribution of the skeletons according to the identifications.

\begin{tabular}{|c|c|c|c|c|c|c|}
\hline NOMBRE & DEFUNCION & EDAD & TALLA & OTROS & UBICACIÓN & FAMILIAR \\
\hline MAD & \multirow{18}{*}{ 07/01/1937 } & 19 & - & Jornalero-UGT & \multirow{3}{*}{$\begin{array}{l}\text { Sepultura } 40 \\
\quad \text { Fila } 7\end{array}$} & $\begin{array}{c}\text { Sobrino hijo } \\
\text { hermano }\end{array}$ \\
\hline GAD & & 37 & - & Jornalero-UGT & & Hijo \\
\hline EAD & & 22 & - & Jornalero-CNT & & $\begin{array}{c}\text { Sobrino hijo } \\
\text { hermano }\end{array}$ \\
\hline JAÁ & & 29 & - & Empleado arbitrios & \multirow{3}{*}{$\begin{array}{l}\text { Sepultura } 41 \\
\quad \text { Fila } 7\end{array}$} & Hijo \\
\hline BBL & & 21 & - & Jornalero & & Hermano \\
\hline SBDLL & & 32 & - & Hortelano-UGT & & Nieto hijo de hijo \\
\hline FCB & & 20 & - & Jornalero & \multirow{3}{*}{$\begin{array}{l}\text { Sepultura } 42 \\
\quad \text { Fila } 7\end{array}$} & - \\
\hline GFH & & 34 & - & Guarda & & - \\
\hline $\mathrm{FGI}$ & & 50 & - & Carnicero & & - \\
\hline AGL & & 24 & - & Jornalero & \multirow{3}{*}{$\begin{array}{l}\text { Sepultura } 44 \\
\quad \text { Fila } 7\end{array}$} & - \\
\hline AGR & & 24 & - & Jornalero & & - \\
\hline DGB & & 25 & - & Jornalero & & $\begin{array}{c}\text { Sobrino hijo } \\
\text { hermana }\end{array}$ \\
\hline PGD & & 40 & - & Labrador & \multirow{3}{*}{$\begin{array}{l}\text { Sepultura } 45 \\
\text { Fila } 7\end{array}$} & - \\
\hline DGM & & 23 & - & Jornalero-UGT & & - \\
\hline HGM & & 26 & - & Jornalero -UGT & & HIJA \\
\hline EGM & & 21 & - & Jornalero & \multirow{3}{*}{$\begin{array}{c}\text { Sepultura } 46 \\
\text { Fila } 7\end{array}$} & - \\
\hline$D G G$ & & 23 & - & Chofer & & - \\
\hline PCB & & 18 & - & Jornalero & & - \\
\hline
\end{tabular}

Tabla 7: Resumen de los datos ante mortem del grupo enterrado el 7 de enero de 1937. En naranja se indica los hermanos CB y en verde los AD. / Ante mortem information of burial group of 7 January 1937. Orange colour indicates the siblings CB and green colour indicates the siblings AD.

tados decúbito supino siguiendo una orientación Sureste-Noroeste (Figura 7 izquierda). Fueron recuperados algunos elementos de la vestimenta (botones, fragmentos de cinturón, suelas de los zapatos de los tres individuos, y en los tres esqueletos fue documentada la presencia de trauma peri mortem. La fosa UE 6.220, albergaba en su interior tres esqueletos decúbito supino orientados Sureste-Noroeste (Figura 7 derecha). Una gruesa capa de cal cubría a los individuos, principalmente la zona torácica y abdominal. Al retirar el bloque de cal se observó la permanencia de una impresión rayada que podría deberse a que el individuo 6.222 vestía una chaqueta de pana (ver SCHOTMANS et al. 2016). En los tres esqueletos fue documentada la pre- 

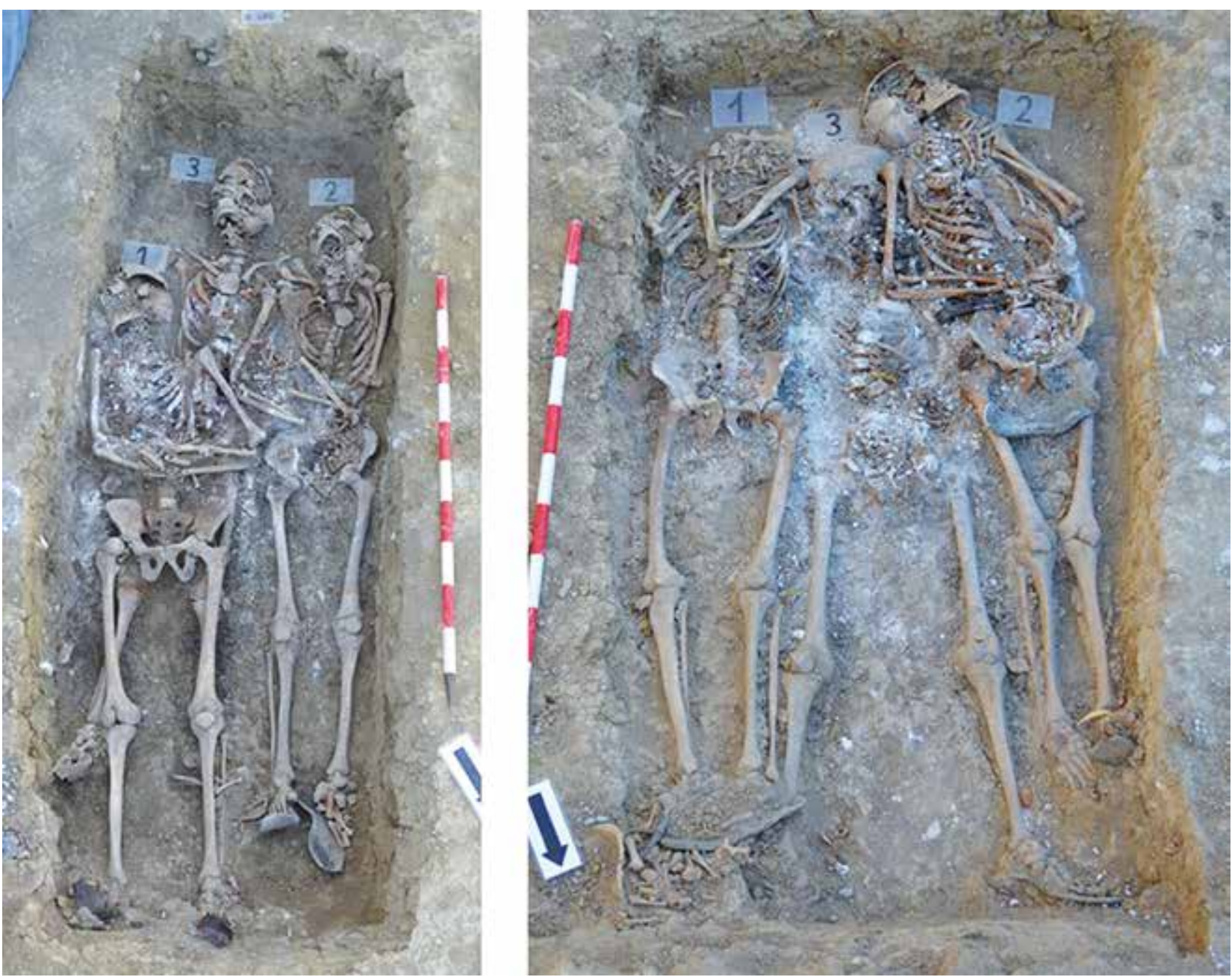

Fig.7. De izquierda a derecha UUEE 6.200 y 6.220. Fosas sin reutilizar del grupo enterrado el 7 de enero de 1937. / From left to right 6.200 and 6.220. Reused graves of the group buried on 7 January 71937.

sencia de trauma peri mortem. Por otro lado, las UUEE $6.210,6.240,6.250$ y 6.260 únicamente contenían un enterramiento individual en decúbito supino cada una. El estudio in situ de los restos determinó que en las tres primeras se trataba de un esqueleto masculino adulto maduro sin trauma peri mortem, mientras que en la UE 6.260 se encontró el esqueleto de una mujer adulta madura también sin trauma peri mortem. En la Figura 8 se muestran estas cuatro UUEE en las que fueron encontrados enterramientos ordinarios en lugar de fosas comunes. Por lo tanto, la excavación mostró que cuatro de las seis sepulturas donde fueron enterrados los hombres de Dueñas fusilados el 7 de enero de 1937 habían sido reutilizadas posteriormente. Solo dos de ellas contenían los enterramientos triples que se esperaban.

En la Tabla VIII se resumen los hallazgos del estudio osteológico de los seis esqueletos procedentes de las fosas no reutilizadas. Todas las estimaciones de sexo fueron masculinas y todos los esqueletos menos uno (6.221) presentaban signos de maduración activa (Figuras 9 y 10). La estimación de la estatura media os- ciló entre 159 y 167 cm. Dos de los esqueletos presentaban como variante anatómica el surco interradicular en los incisivos laterales superiores, 6.221 en el izquierdo y 6.223 bilateral (Figura 11), una variante dental con una frecuencia media en poblaciones europeas menor de 35\% (SCOTT y IRISH, 2017).

Aunque el número de esqueletos recuperados era inferior al de personas buscadas en este grupo, conociendo la dinámica cementerial del Cementerio Viejo y teniendo en cuenta que hay compatibilidad entre los datos ante mortem y los datos osteológicos referentes a sexo y edad, se decidió trabajar con la hipótesis de grupo cerrado y orientar las pruebas genéticas para intentar alcanzar alguna identificación. En primer lugar, la presencia del hijo de uno de los hermanos AD, concretamente del de mayor edad (37 años), llevó a proponer el estudio de los STRs de 6.221, el único esqueleto recuperado que no presentaba signos de maduración activa, resultando coincidente con la muestra del familiar. Una vez identificado 6.221 como GAD, se extrajeron los Y-STRs de este esqueleto, que se utilizaron como 

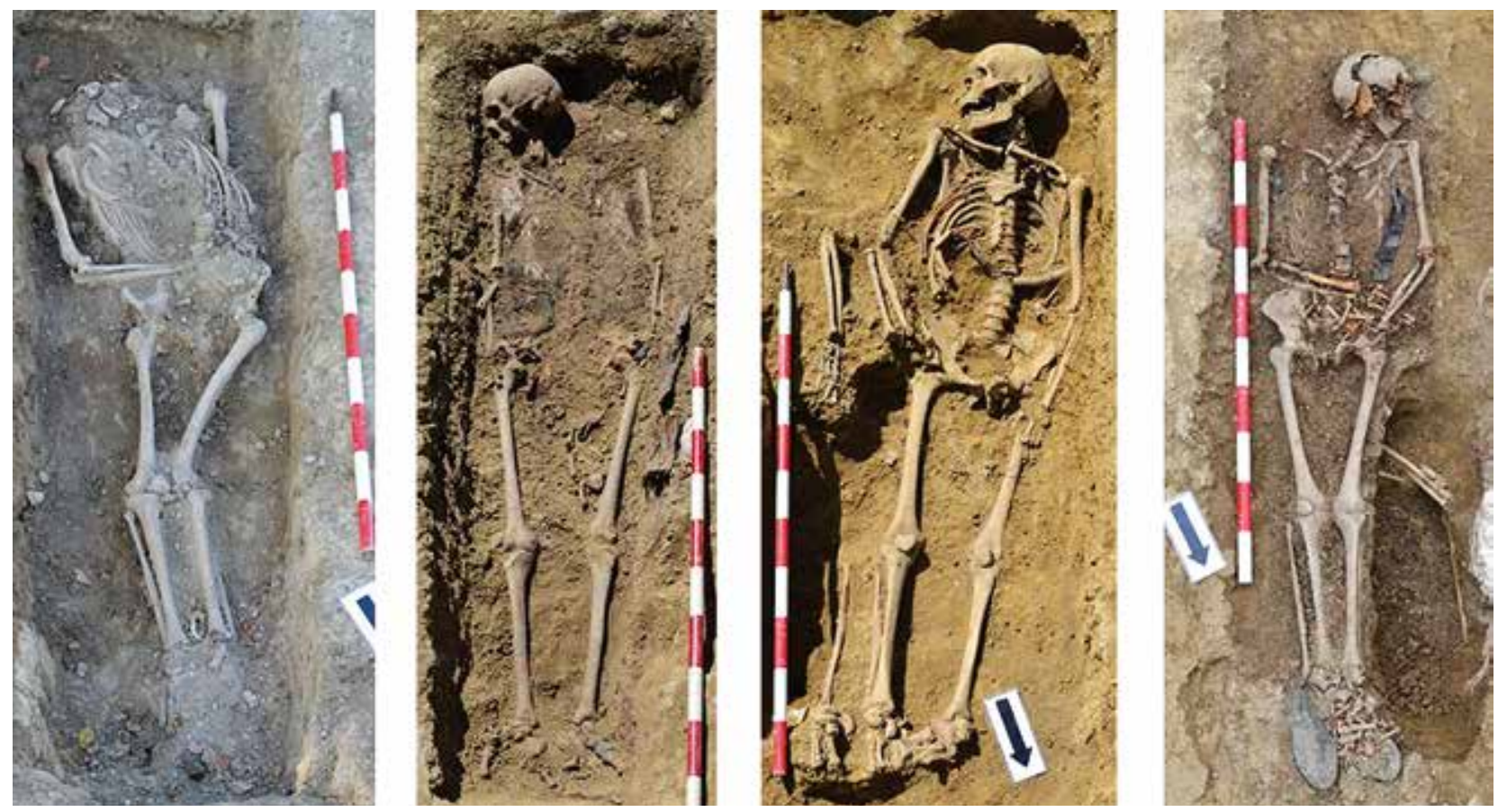

Fig.8. De izquierda a derecha UUEE 6.210, $6.240,6.250$ y 6.260. Enterramientos ordinarios ocupando el lugar de los represaliados que forman el grupo enterrado el 7 de enero de 1937. / From left to right 6.210, 6.240, 6.250 and 6.260. Ordinary burials in the place where was expected the graves corresponding to the group buried on 7 January 1937.

\begin{tabular}{|c|c|c|c|c|c|}
\hline UE fosa & UE esqueleto & SEXO & EDAD & TALLA & OBSERVACIONES \\
\hline \multirow{3}{*}{6.200} & 6.201 & $\mathrm{M}$ & $<32^{\mathrm{B}}$ & $167.5 \pm 6.96^{\mathrm{D}}$ & - \\
\cline { 2 - 6 } & 6.202 & $\mathrm{M}$ & $\leq 18^{\mathrm{A}}$ & $159.5 \pm 6.96^{\mathrm{D}}$ & - \\
\cline { 2 - 6 } & 6.203 & $\mathrm{M}$ & $<32^{\mathrm{B}}$ & $159.5 \pm 6.96^{\mathrm{D}}$ & - \\
\hline \multirow{3}{*}{6.220} & 6.221 & $\mathrm{M}$ & $28.7(21-46)^{\mathrm{C}}$ & $161.4 \pm 6.96^{\mathrm{D}}$ & Surco interradicular incisivo lateral superior izquierdo \\
\cline { 2 - 6 } & 6.222 & $\mathrm{M}$ & $<32^{\mathrm{B}}$ & $161.6 \pm 6.96^{\mathrm{D}}$ & - \\
\cline { 2 - 6 } & 6.223 & $\mathrm{M}$ & $\leq 18^{\mathrm{A}}$ & $163.7 \pm 6.96^{\mathrm{D}}$ & Surco interradicular bilateral incisivos laterales superiores \\
\hline
\end{tabular}

Tabla 8: Resumen estudio osteológico. Sexo masculino. B: estimación de la edad en base a Langley-Shirley y Jantz (2010). C: estimación de la edad en base a Suchey y Brooks (1986). A: estimación de estatura por método anatómico de Raxter (2006). D: estimación de estatura por método matemático de Mendoça (2000). / Osteological findings of the 10 March 1937 group. Male. B: age range from Langley-Shirley y Jantz (2010). C: age range from Suchey y Brooks (1986). A: stature from Raxter (2006). D: stature from Mendoça (2000).
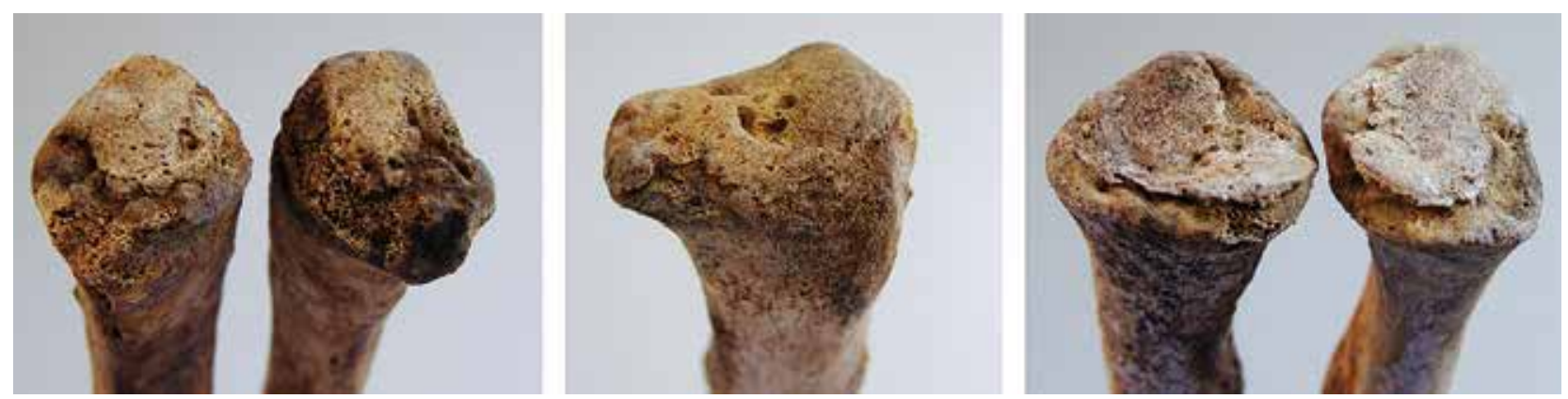

Fig.9. De izquierda a derecha, 6.201, 6.203 y 6.222. Epífisis medial de las clavículas con fusión activa. / From left to right 6.201, 6.203 and 6.222. Active fusion at the medial end of the clavicle.

muestra de referencia para el estudio de los Y-STRs del esqueleto 6.223. Este esqueleto era compatible con MAD sobre la base de la edad estimada (igual o menor a 18 años) y documentada (19 años), y se obtuvo una coincidencia para los Y-STR entre ambos esqueletos. Además, estos dos esqueletos eran los únicos de este grupo que presentaban el anteriormente mencionado surco interradicular (Figura 11). 

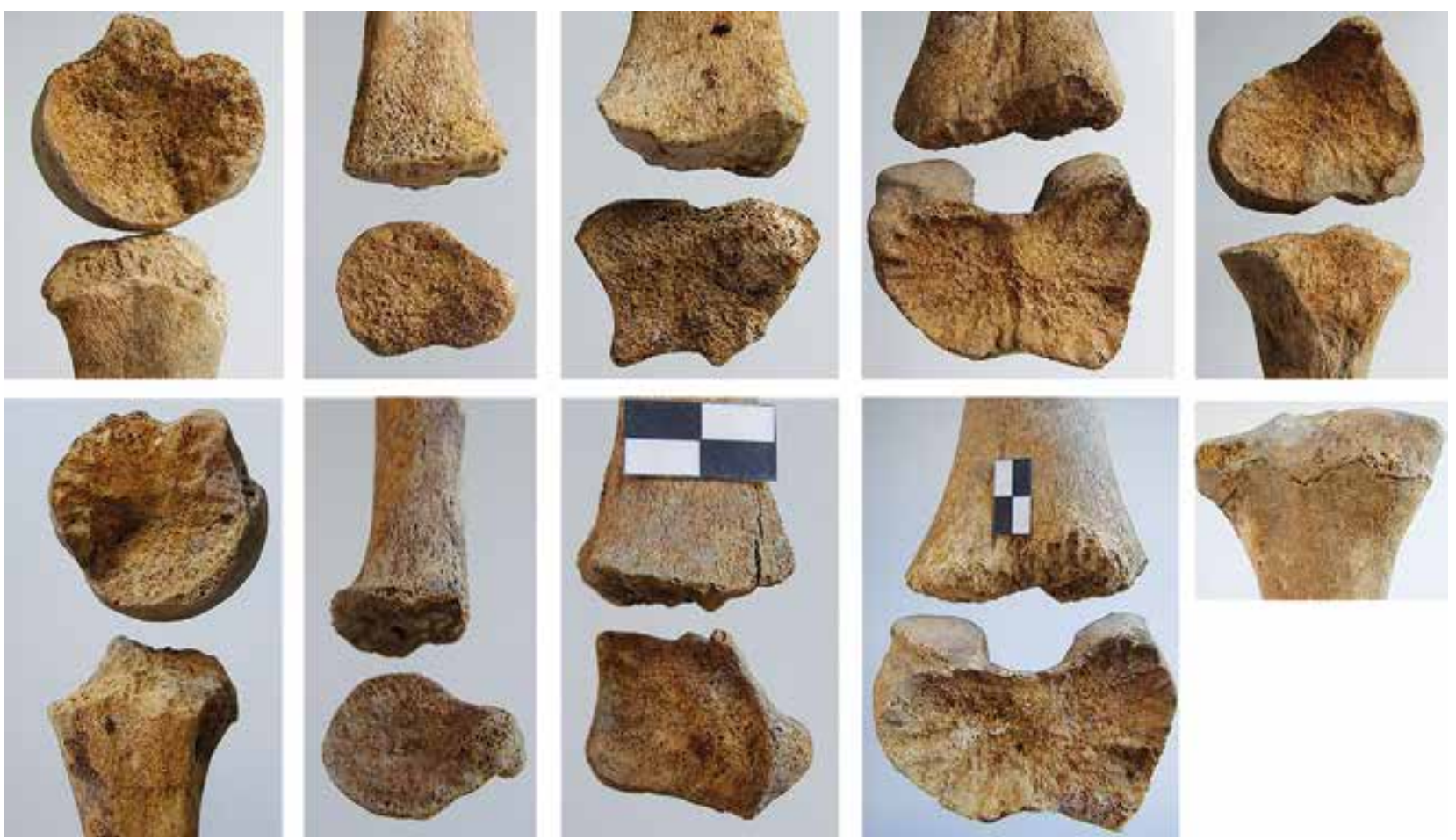

Fig.10. Arriba 6. 202 y abajo 6.223. De izquierda a derecha. Epífisis proximal de húmero; epífisis distales de cúbito, radio y fémur; epífisis proximal de tibia. / Top 6.202 and bottom 6.223. From left to right. Proximal humeral epiphysis; distal epiphysis of ulna, radius and femur. Proximal tibia epiphysis.
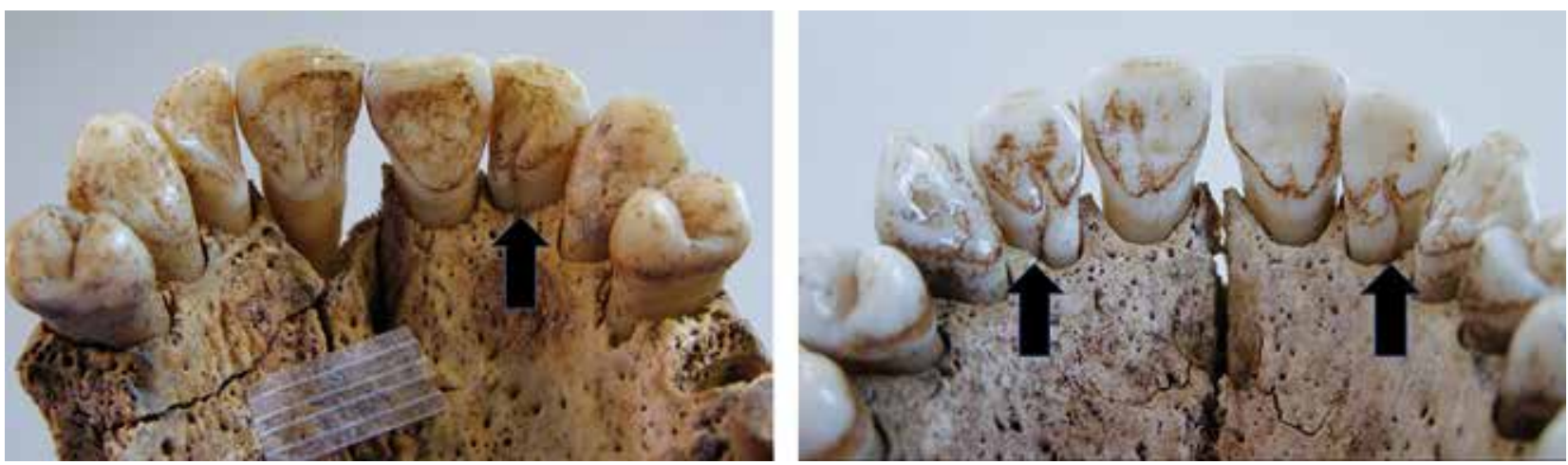

Fig.11. Izquierda. 6.221 surco interradicular en incisivo lateral izquierdo. Derecha. 6.223 surco interradicular bilateral en incisivos laterales. / Left. 6.221. Palato radicular groove in upper lateral left incisor. Right. 6.223. Bilateral palato radicular groove, in upper lateral incisors.

Para la identificación de BBL se tenía muestra de un hermano por lo que se realizó el estudio de los Y-STRs, encontrándose coincidencia únicamente entre el esqueleto 6.202 y la muestra del familiar. Este esqueleto presentaba varias epífisis sin fusionar, por lo que le fue asignada una edad igual o inferior a 18 años, mientras que las partidas de nacimiento y defunción indicaban que BBL tenía 21 años en el momento del fallecimiento. Una edad ósea en el extremo o fuera de la variabilidad asociada a la edad cronológica descrita en las referencias puede deberse a que esta persona fuese un madurador tardío y/o a la posibilidad de que la edad ósea en la población rural española del periodo de la guerra civil se encuentre retrasada respecto a los referentes más comúnmente empleados en osteología para estimar la edad de muerte. Retrasos de este tipo asociados a las condiciones de vida han sido observados en la fusión de la epífisis esternal de la clavícula (MEIJERMAN et al., 2007).

Para la identificación de HGM se tenía la muestra de una hija lo que llevó a proponer el estudio de los STRs del esqueleto 6.222, resultando coincidentes con la muestra del familiar. El análisis genético de los dos esqueletos sin identificar (6.201 y 6.203) resultaron negativos para SBdIL, EAD y JAÁ. En la Tabla IX se resumen las identificaciones obtenidas.

El grupo de Dueñas ejemplifica cómo funciona el proceso de identificación en los llamados grupos parciales. A pesar de que el número de esqueletos recu- 


\begin{tabular}{|c|c|c|c|c|c|}
\hline SEPULTURA & NOMBRE & EDAD & UE & EDAD & OBSERVACIONES \\
\hline SEP 40 FILA 7 & GAD & 37 & 6.221 & 28.7 (21-46) & $\begin{array}{c}\text { Surco interradicular incisivo lateral } \\
\text { superior izquierdo }\end{array}$ \\
\cline { 2 - 6 } & MAD & 19 & 6.223 & $\leq 18$ & $\begin{array}{c}\text { Surco interradicular bilateral incisivos } \\
\text { laterales superiores }\end{array}$ \\
\hline SEP 41 FILA 7 & BBL & 21 & 6.202 & $\leq 18$ & Y-STRS (15) \\
\hline SEP 45 FILA 7 & HGM & 26 & 6.222 & $\leq 32$ & STRS (16) \\
\hline
\end{tabular}

Tabla 9: Resumen de las identificaciones obtenidas en el grupo enterrado el 7 de enero de 1937. / Summary of the identifications from the group buried the 7 of January 1937

perado es inferior al que se esperaba debido a la reutilización de sepulturas en los años cuarenta, la hipótesis de grupo cerrado sigue funcionando, construida sobre la compatibilidad entre los datos de localización de las fosas en el cementerio y los hallazgos arqueológicos, entre los datos ante mortem de las personas buscadas y los resultados osteológicos, y sobre la coincidencia de las pruebas genéticas dirigidas dentro del universo de identificación de la Carcavilla.

En este caso, volvemos a observar que no hay correspondencia exacta entre la distribución de cadáveres en las sepulturas que indicaba el LRC y la distribución de esqueletos que muestran las identificaciones (Figura 12). Según el LRC, HGM fue enterrado en la sepultura 45 de la fila 7 y sin embargo su esqueleto fue recuperado en la sepultura 42. Igualmente, según el LRC los tres hermanos AD fueron enterrados en la sepultura 40 de la fila 7 , sin embargo, el proceso de identificación refleja que ninguno de ellos fue enterrado allí, encontrándose dos de sus cuerpos en la sepultura 42. Tampoco hay coincidencia en el caso de BBL, enterrado en la sepultura 41 de la fila 7 según el LRC y recuperado en la sepultura 40 . Este intercambio de esqueletos evidencia un engaño hacia las familias que, cinco años después de la inhumación, pagaban un contrato de arrendamiento para mantener las sepulturas, ya que no era posible garantizar qué esqueletos permanecían en la sepultura y qué esqueletos eran arrojados al osario para permitir nuevas inhumaciones. La Figura 13 muestra las solicitudes de arrendamiento por las sepulturas

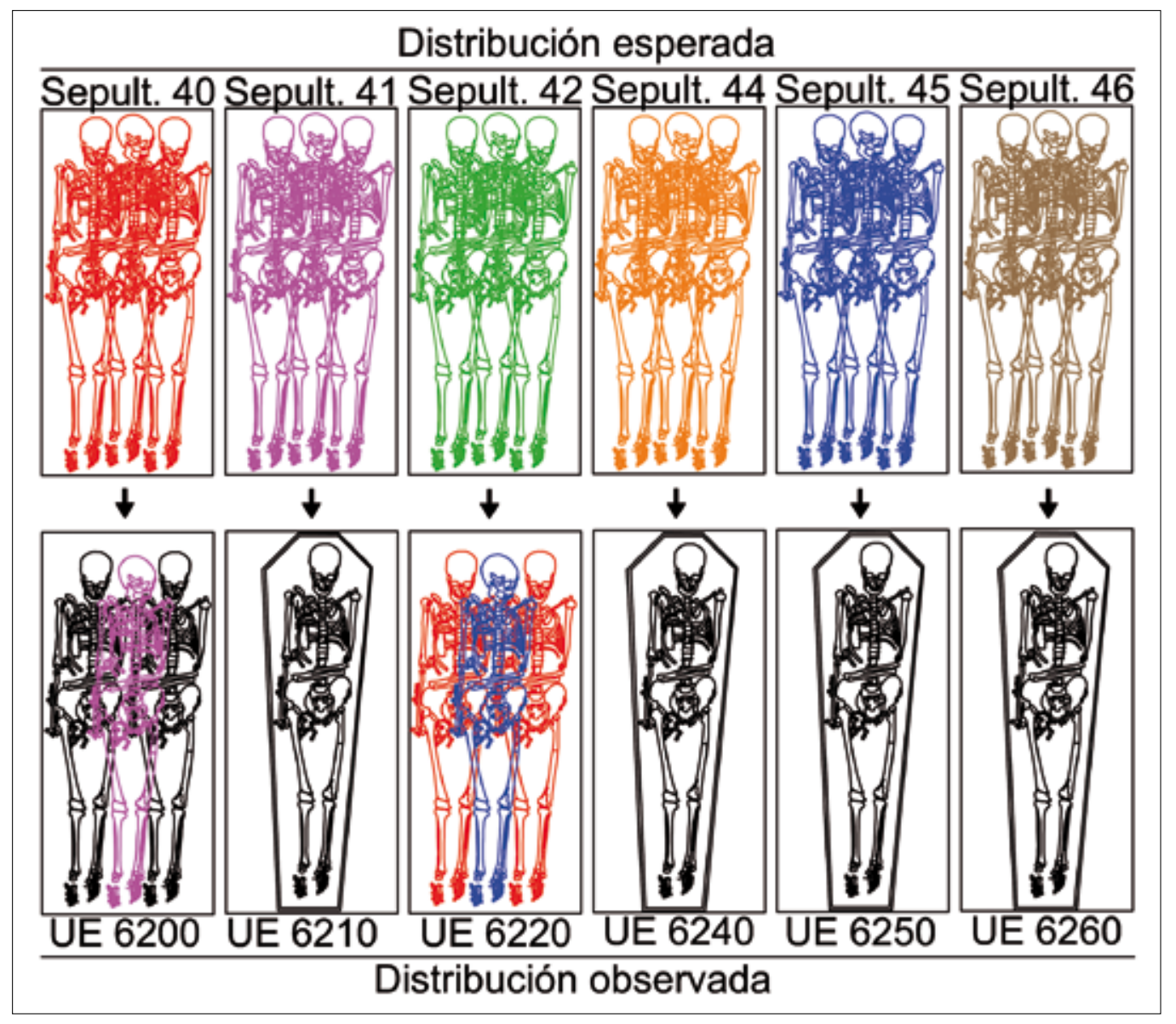

Fig.12. Arriba. Representación de la distribución de los cadáveres en las sepulturas 40, 41, 42, 44, 45 y 46 de la fila 7 según el LRC. Abajo. Representación de la distribución real de los esqueletos una vez alcanzadas las identificaciones. Los esqueletos de color negro de la UE 6.200 no se han identificado. Top. Representation of the distribution of the corpses in graves 40, 41, $42,44,45$ and 46 of row 7 , according to the CRB. Botton. Representation of the real distribution of the skeletons according to the identifications. Black skeletons into 6.200, have not been identified. 


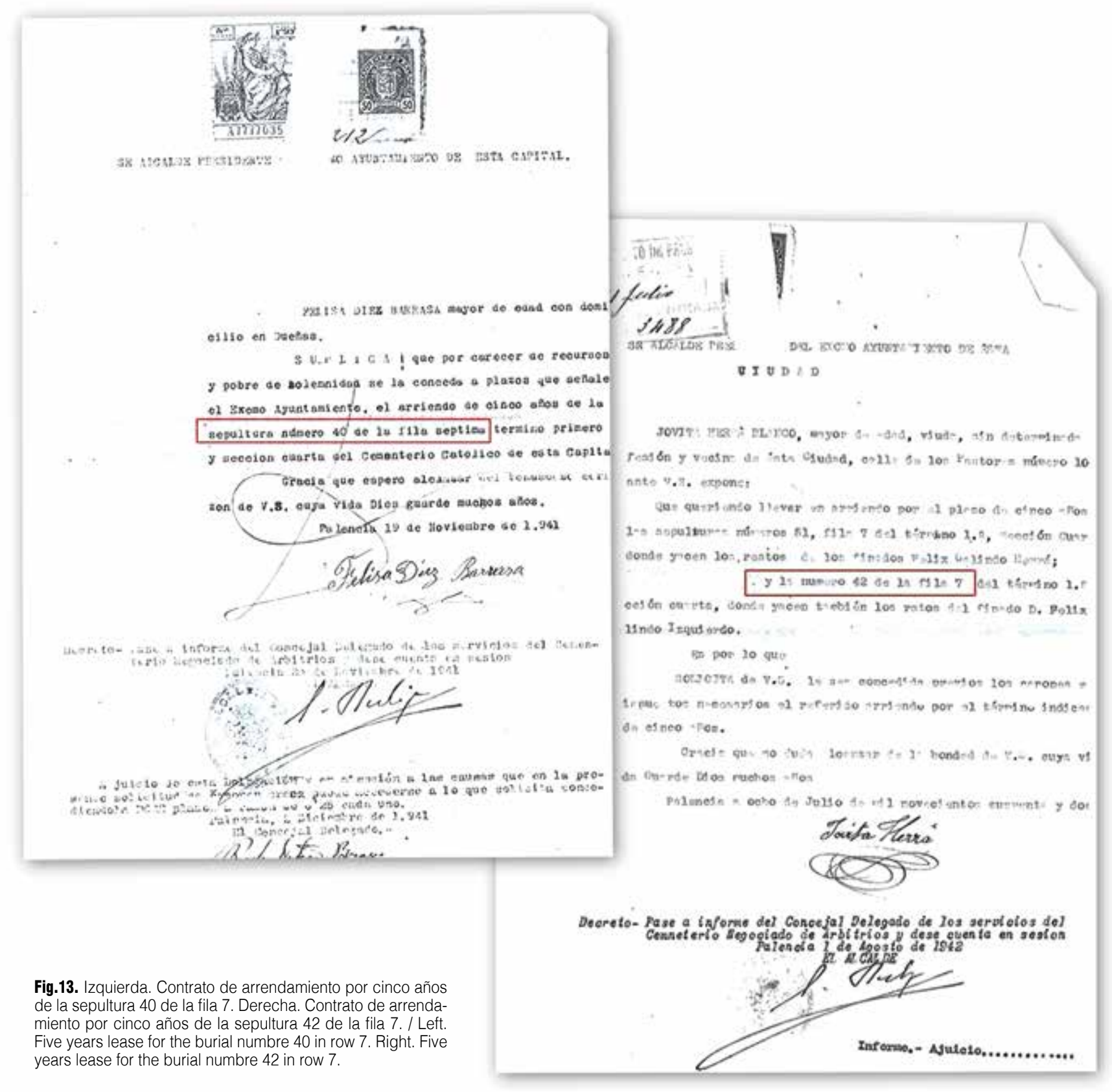

40 y 42 de la fila 7 . En el arriendo de la sepultura 40 podemos leer que Felisa Díez Barrasa, madre de los tres hermanos DA supuestamente enterrados en esa sepultura según el LRC, "suplica que por carecer de recursos y pobre de solemnidad se la conceda a plazos que señale el Excmo Ayuntamiento, el arriendo de cinco años de la sepultura número 40 de la fila séptima término primero y sección cuarta del Cementerio Católico de esta Capital" el 19 de noviembre de 1941, solicitud que se concede "a doce plazos a razón de 6,25 cada uno". El análisis osteológico y genético refleja que en la sepultura 40 no fue enterrado ninguno de los hermanos AD. Sin embargo, dos de ellos fueron enterrados en la sepultura 42 (UE 6.220), junto a HGM, según el análisis osteológico y genético. Sus restos permanecen ahí porque otra mujer, Jovita Herrá, pagó el arriendo para conservar la sepultura de su esposo, FGI, lo que, según refleja la investigación, no ocurrió.

\section{GRUPO AUSENTE}

La investigación a partir de los testimonios y los archivos indicaba que ocho hombres de Cevico Navero fueron fusilados y enterrados en el Cementerio Viejo de Palencia el 29 de abril de 1937. Estos hombres eran Paulino González Gimeno, Daniel Muñoz de Juana, 
Emiliano Muñoz de Juana, Eusebio Muñoz de Juana, Gregorio Baldazo Carrasco, Lucio Fernández Campos, Anastasio Muñoz Alejos y Justo Otero Martínez. La información ante mortem se resume en la Tabla X. De cara a la identificación, cabe destacar la presencia de un grupo de tres hermanos, los hermanos Muñoz de Juana (MdJ). Además, hay familiares de un represaliado para el cotejo genético. Según el LRC estas ocho personas fueron enterradas en las sepulturas 21 y 22 de la fila 9 del Término $1^{\circ}$ Sección $3^{\mathrm{a}}$ formando dos enterramientos cuádruples.
Estas sepulturas fueron identificadas tentativamente como las UUEE 6.070 y 6.080 , excavadas en la campaña de 2011. La UE 6.070, albergaba dos enterramientos individuales, UUEE 6.071 y 6.072, uno sobre otro, ambos en ataúd. 6.071 correspondía a un individuo masculino, adulto joven, que presentaba signos de autopsia en las costillas, sin trauma peri mortem. 6.072 correspondía, según las observaciones realizadas en campo, a un individuo de sexo masculino, adulto maduro, también sin signos de trauma peri mortem (Figura 14).

\begin{tabular}{|c|c|c|c|c|c|c|}
\hline NOMBRE & DEFUNCION & EDAD & TALLA & OTROS & UBICACIÓN & FAMILIAR \\
\hline DMdJ & \multirow{8}{*}{ 29/04/1937 } & 40 & - & Jornalero & \multirow{4}{*}{$\begin{array}{l}\text { Sepultura } 21 \\
\text { Fila } 9\end{array}$} & - \\
\hline EMdJ & & 45 & - & Jornalero-concejal & & - \\
\hline EUMDJ & & 50 & - & Jornalero & & - \\
\hline PGJ & & 44 & - & Jornalero-concejal & & - \\
\hline GB & & 30 & - & Jornalero-Alcalde & \multirow{4}{*}{$\begin{array}{c}\text { Sepultura } 22 \\
\text { Fila } 9\end{array}$} & - \\
\hline LFC & & 34 & - & Jornalero-Tntealcalde & & - \\
\hline AMA & & 33 & - & Jornalero-concejal & & Sobrino materno \\
\hline JOM & & 31 & - & Jornalero-concejal & & - \\
\hline
\end{tabular}

Tabla 10: Información ante mortem del grupo enterrado el 29 de abril de 1937. En verde se señalan los hermanos MdJ. / Ante mortem information of burial group of 29 April 1937. Green colour indicates a kinship group, the siblings MdJ.
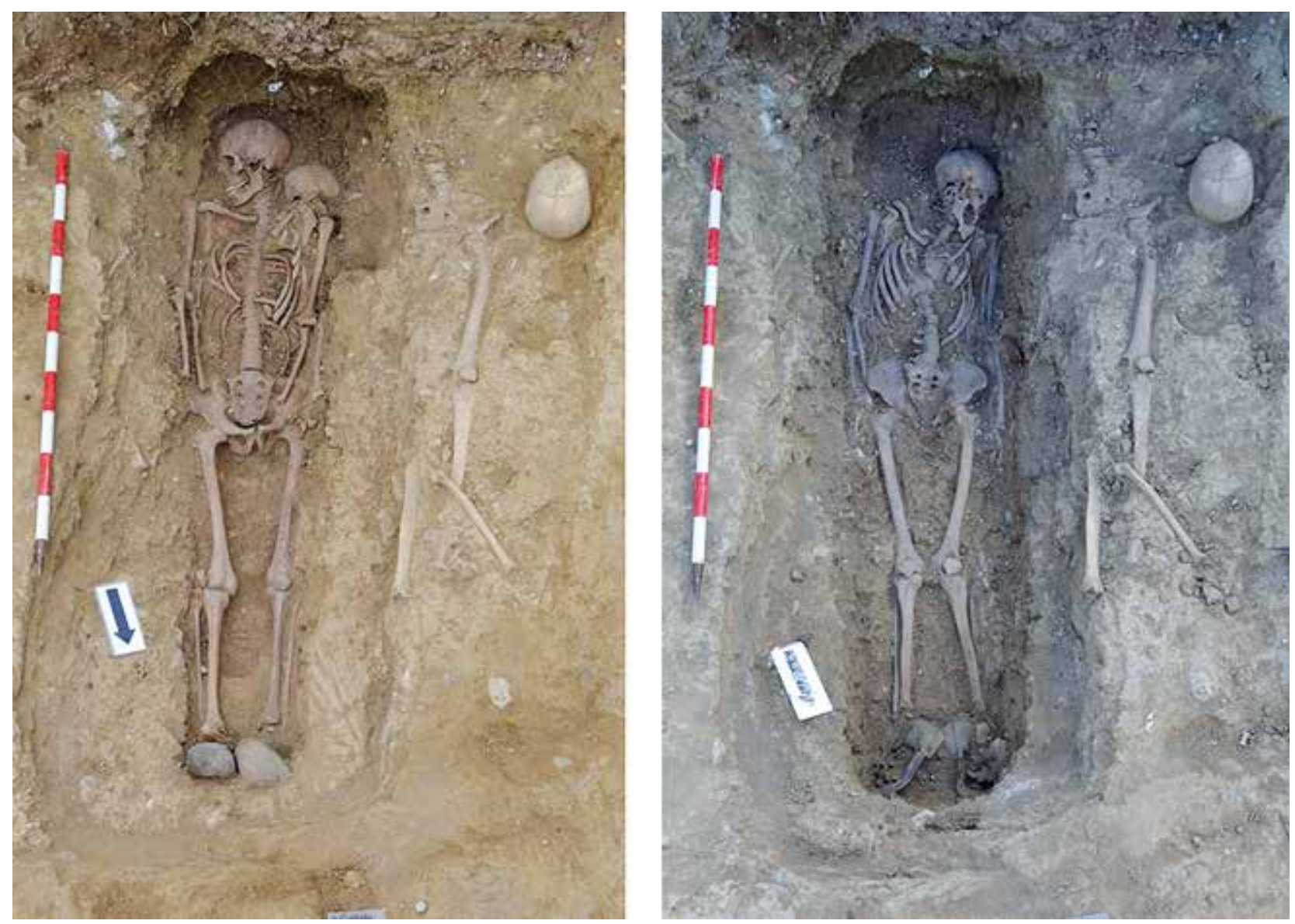

Fig.14. Sepultura UE 6.070. Izquierda 6.071. Derecha 6.072. / Burial 6.070. Left, skeleton 6.071. Right, skeleton 6.072. 
La UE 6.080 albergaba, en un primer nivel, dos enterramientos individuales en féretro, tratándose de un individuo perinatal (UE 6.081) y un individuo de sexo femenino, adulto joven (UE 6.082). Al continuar la excavación de la sepultura fueron localizados restos óseos correspondientes a cuatro individuos adultos. El individuo 6.083, formado por cráneo, columna cervical y torácica, hemi tórax y brazo derechos, con signos de trauma peri mortem en cráneo, mandíbula y costillas. El individuo 6084 , del que se conservaban la tibia, peroné y pie izquierdos articulados. Otro individuo, UE 6085, formado solamente por las dos primeras vértebras cervicales, atlas y axis, articuladas. Y finalmente, el individuo 6.086 , del que se conservaba parte del pie izquierdo articulado (cuboides, escafoides, $2^{\circ}$ y $3^{\circ}$ cuneiformes, metatarsos, falanges proximales, dos falanges mediales y dos distales). También fue documentada la presencia de cal. La disposición de los restos permite interpretar que dos cuerpos fueron depositados orientados al sur y otros dos al norte (Figura 15). Los restos representados en las UUEE 6.083 a 6.086, correspondientes a cuatro individuos adultos, con signos de trauma peri mortem, acompañados de cal y orientados en dos direcciones opuestas, resultaban compatibles con los represaliados de Cevico Navero. La fosa 6.080 reflejaba que, en algún momento posterior al enterramiento de 1937, la sepultura había sido reutilizada. Los restos esqueléticos de los represaliados habrían sido retirados (parcialmente) para dejar espacio a los dos enterramientos posteriores.

El estudio osteológico de los restos se vio comprometido por la escasa representación de 6.084, 6.085 y 6.086 principalmente (Figura 16). Sobre el análisis osteológico de 6.083, el análisis visual del cráneo determinó que correspondía a un individuo masculino. En la clavícula y demás restos preservados no se observaron signos de maduración activa, por lo que se consideró un individuo adulto maduro. En el cráneo se observaron fracturas de origen peri mortem en el temporal y occipital derechos, así como en la base del cráneo. En el ángulo mandibular izquierdo se observó lo que sería parte de un orificio de salida de proyectil de arma de fuego, sobre la base de parte de un bisel externo y cuatro fracturas radiales asociadas. Estas fracturas describirían una trayectoria de disparo de derecha a izquierda. (Figura 17).

Para tratar de confirmar a través de la genética la hipótesis de que los restos óseos recuperados correspondieran a los represaliados de Cevico Navero enterrados en las sepulturas 21 y 22 de la fila 9 , se plantearon una serie de análisis. Puesto que la única muestra de familiar disponible correspondía a un sobrino materno de AMA y se conocía la presencia de un grupo de tres hermanos, se planteó el análisis de ADN mitocondrial de los restos óseos. Estos consistían en dos molares de 6.083, el primer y segundo metatarso izquierdo de 6.084 y de 6.086 y el axis de 6.085. De los restos óseos de 6.085 y 6.086 no fue posible la extracción de ADN mitocondrial. De los molares de 6.083 sí fue posible la extracción de ADN mitocondrial y de 6.084 también, aunque sólo pudo amplificarse la región HVI. La región HVI de ambos esqueletos (6.083 y 6.084) es coincidente entre sí pero no es coincidente respecto a la indubitada. El siguiente paso consistiría en el estudio de STRs del cromosoma Y de los cuatro restos esqueléticos para descartar o abrir la posibilidad de que entre ellos se encuentran los tres hermanos, pero no pudo realizarse por terminarse el presupuesto del proyecto. El grupo de Cevico Navero muestra las dificultades para confirmar la hipótesis de grupo cerrado en lo que hemos llamado grupos ausentes. Sin embargo, la recuperación de los restos esqueléticos en una de las fosas identificadas tentativamente como las correspondientes con el grupo, permitió elaborar la interpretación de las reutilizaciones.

En total, a lo largo del proyecto se obtuvieron 57 identificaciones, 51 de ellas con prueba genética (Tabla $X I)$, y seis sin prueba genética (Tabla XII). Como se puede observar en la Tabla XI, hay diversidad en cuanto al tipo de pruebas genéticas sobre las que se basa cada identificación (STRs, Y-STRs, mtDNA) y, en el caso de los STRs e Y-STRs, en cuanto al número de sistemas obtenidos. En algunos casos el número de sistemas obtenidos es bajo (de 8 a 12), lo que en principio podría abrir la posibilidad de los denominados falsos positivos o coincidencias al azar, observados previamente en casos de identificación de víctimas de violaciones de derechos humanos en la antigua Yugoslavia (BIRUS et al., 2003; GORNIK et al., 2002).

En estos casos, el motor del proceso de identificación es el cruce de perfiles genéticos entre bases de datos de familiares y de restos exhumados. Por el contrario, en La Carcavilla, y en general en los procesos de identificación de víctimas de la guerra civil española, la prueba genética no es el motor inicial del proceso de identificación, sino que es la prueba final de un proceso basado en la hipótesis de presencia de un grupo cerrado, como se ha ejemplificado en los casos presentados. En el caso de La Carcavilla, la investigación realizada es un ejemplo de intervención antropológico forense multidisciplinar, que implicó la coordinación de distintas agrupaciones de familiares, la búsqueda de documentación en distintos archivos, la confección de un plano para orientar la búsqueda, la realización de distintas actuaciones arqueológicas, estudios osteológicos y análisis genéticos. La identificación de los restos exhumados, objetivo de la intervención, se basó en el cruce de información procedente de diversas fuentes, documental, arqueológica, osteológica y genética, que fueron trabajadas de forma independiente en un primer momento y después integradas en la línea de lo que se ha denominado el informe pericial integrado (ETXEBERRÍA, 2010). Pero aun teniendo en cuenta los resultados razonables obtenidos en el proceso de identificación en La Carcavilla y en otros casos, es necesario indicar la necesidad de una base de datos genética de víctimas de la guerra civil española estructurada a 

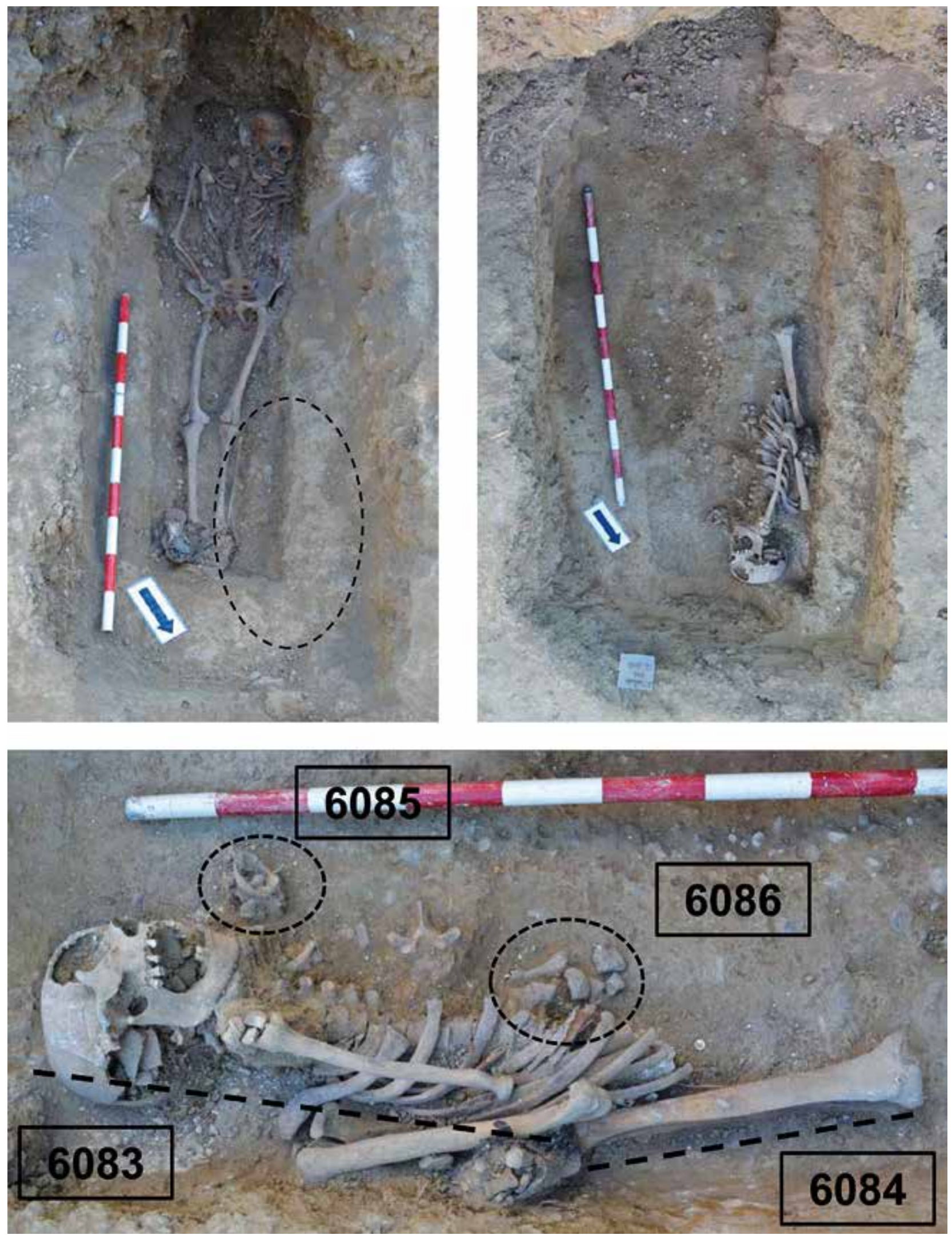

Fig.15. UE 6.080. Arriba izquierda, 6.082. En negro se indica el lugar donde se sitúan 6083, 6084, 6085 y 6086. Abajo. Vista en detalle de las cuatro UUEE. / Burial 6.080. Top left, skeleton 6.082. The black circle points the place where $6.083,6.084,6.085$ and 6.086 will be find. Bottom. Detail of the position of 6.083 , $6.084,6.085$ and 6.086 

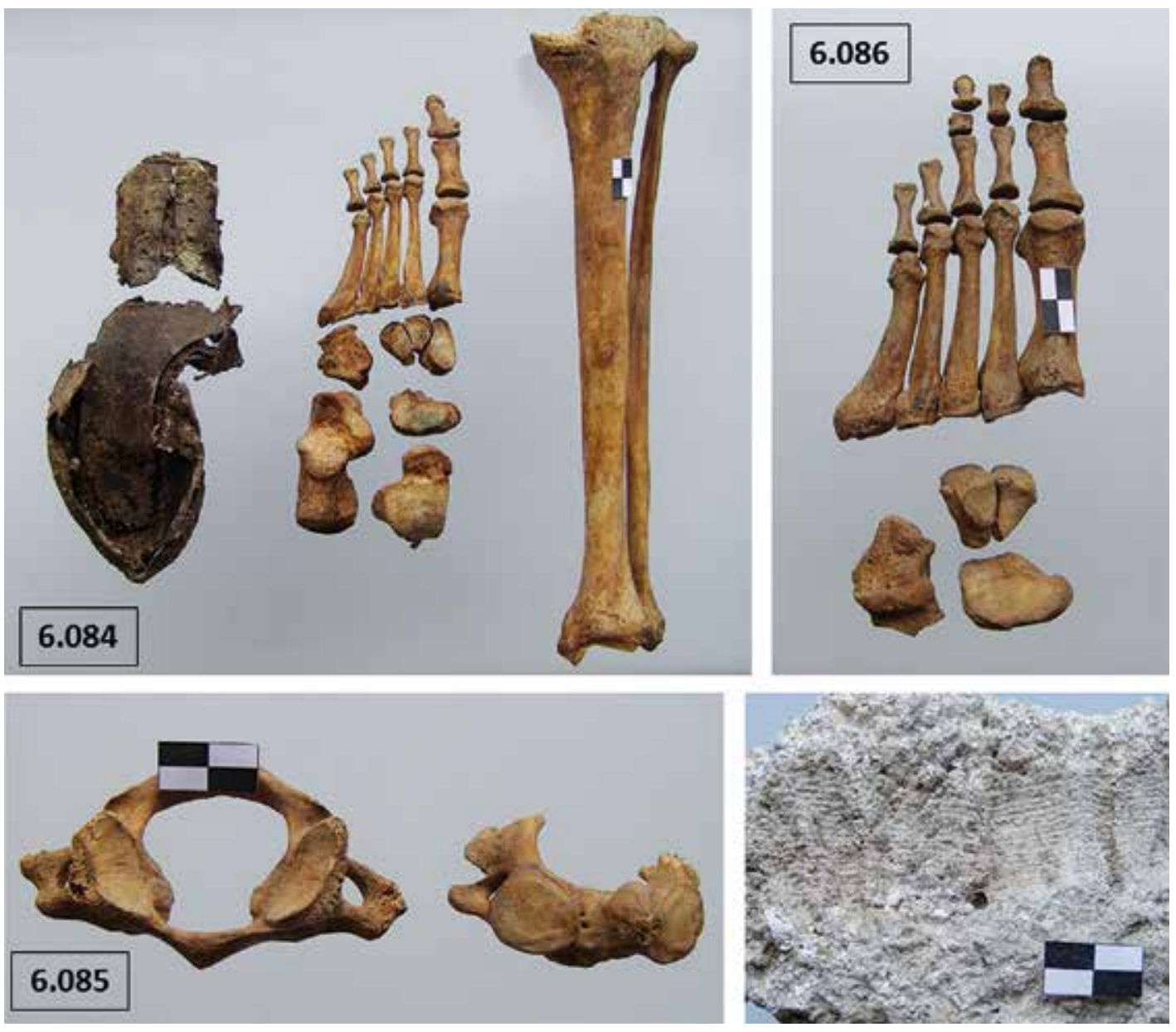

Fig.16. UUEE 6.084, 6.085 y 6.086 en laboratorio. Abajo a la derecha, bloque de cal recuperado junto a los cuerpos en el que se aprecia la impronta del tejido que vestían I Bones of 6.084 , 6.085 and 6.086 in the lab. Right bottom, part of the lime cast recovered from grave with preserved imprints of the corduroy wore by the individuals.

\begin{tabular}{|c|c|c|c|}
\hline $\begin{array}{c}\text { PRUEBA } \\
\text { GENÉTICA }\end{array}$ & SISTEMAS & ESQUELETOS & TOTAL \\
\hline \multirow{6}{*}{ STRs } & 8 & 4 & \multirow{6}{*}{21} \\
\hline & 9 & 1 & \\
\hline & 14 & 2 & \\
\hline & 15 & 3 & \\
\hline & 16 & 9 & \\
\hline & 21 & 2 & \\
\hline \multirow{7}{*}{ Y-STR } & 8 & 1 & \multirow{7}{*}{19} \\
\hline & 10 & 1 & \\
\hline & 11 & 2 & \\
\hline & 12 & 2 & \\
\hline & 14 & 2 & \\
\hline & 15 & 5 & \\
\hline & 16 & 6 & \\
\hline mtDNA & - & 10 & 10 \\
\hline STRs / Y-STR & - & 1 & 1 \\
\hline \multicolumn{3}{|c|}{ TOTAL } & 51 \\
\hline
\end{tabular}

Tabla 11: Resumen del tipo de prueba genética en la que se basa cada identificación propuesta. / Summary of the type of genetic study on which each proposed identification is based. nivel provincial, autonómico o nacional, para una correcta centralización de los datos, así como también la necesidad de que estos procesos de identificación cuenten con la financiación adecuada, ya que, en muchos casos, como en la Carcavilla, el límite de financiación determina que no se puedan realizar todas las pruebas necesarias. En el caso de las seis identificaciones sin prueba genética, se trataba de casos sin familiares solicitantes, pero la corroboración de información de diversas fuentes (Tabla XII, Figura 18) se consideró suficiente para dar los seis esqueletos como identificados.

En un contexto más amplio del desarrollo histórico de las investigaciones antropológico forenses de graves violaciones de derechos humanos, desde las primeras experiencias multidisciplinares latinoamericanas a finales de la década de los ochenta del siglo pasado (DORETTI y SNOW, 2003), cristalizadas en protocolos internacionales (e.g. Minnesota) y en las primeras investigaciones y tribunales internacionales desde la segunda guerra mundial (e.g. Ios de la antigua Yugoslavia y Ruanda), a la expansión de las investigaciones antropológico forenses de graves violaciones de derechos humanos (STEADMAN y HAGLUND, 2005; KIMMERLE 

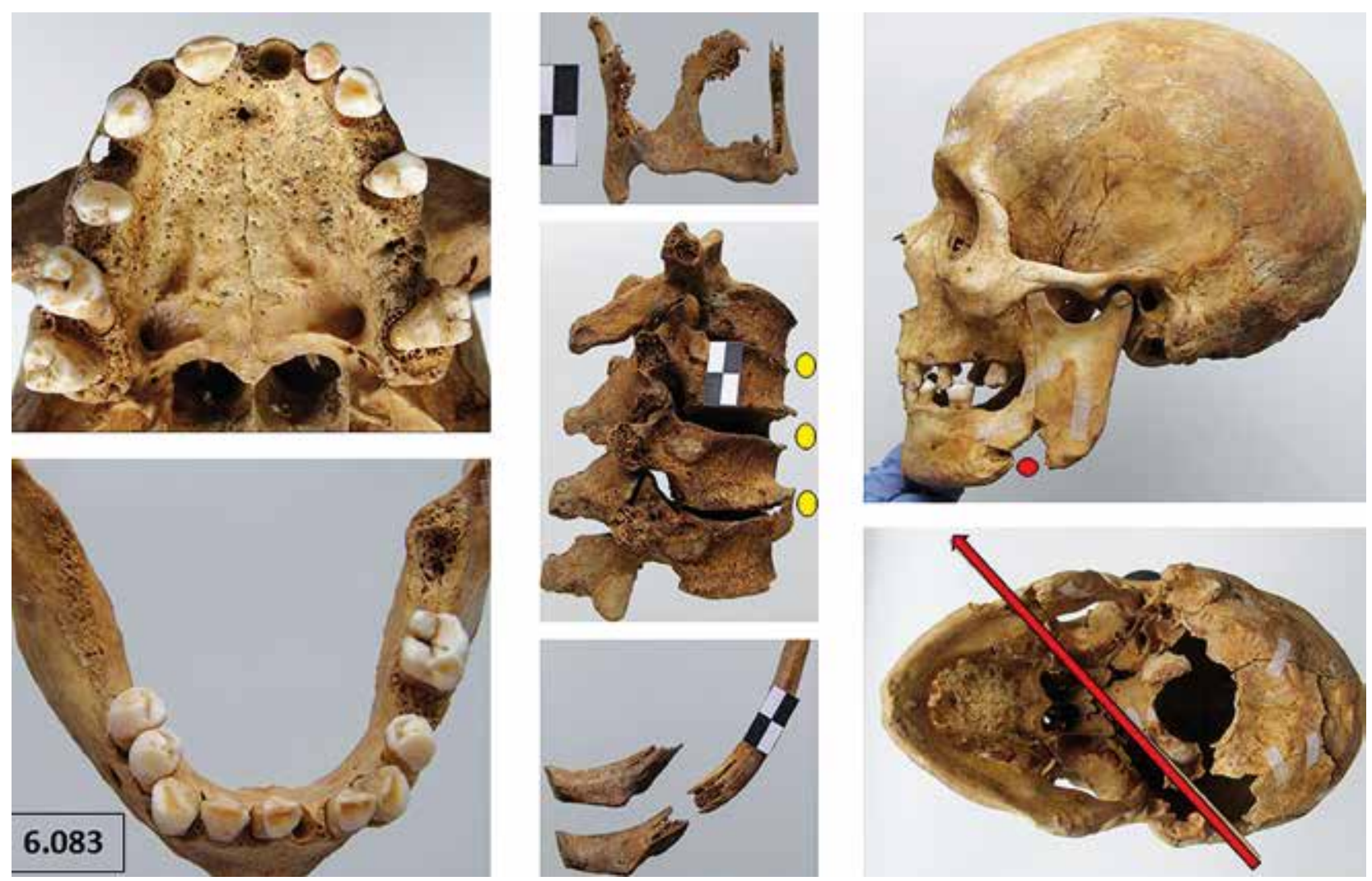

Fig.17. UE 6.083. Izquierda. Dentición. Centro, de arriba abajo. Cartílago tiroides osificado, osteofitos a nivel de las vértebras torácicas bajas y trauma peri mortem en costillas. Derecha. Arriba, orificio de salida en mandíbula. Abajo, trayectoria del disparo. / 6.083. Left row. Dentition. Middle row, from top to bottom. Ossified thyroid cartilage. Lower thoracic vertebrae with advanced signs of degenerative disease. Perimortem fractures at ribs. Right row, from top to bottom. Gunshot wound to the mandible. Path of the shot.

\begin{tabular}{|c|c|c|c|c|c|c|c|}
\hline \multicolumn{4}{|c|}{ INFORMACIÓN ANTE MORTEM } & \multicolumn{4}{|c|}{ IDENTIFICACIÓN } \\
\hline GRUPO & UBICACIÓN & NOMBRE & EDAD & UE ESQ & EDAD & OTROS & DNA \\
\hline \multirow{3}{*}{ 01/09/1936 } & \multirow{3}{*}{$\begin{array}{l}\text { Sepultura } 43 \\
\quad \text { Fila } 3\end{array}$} & $\mathrm{CBB}$ & 48 & 13.313 & $35.2(23-57)$ & \multirow{3}{*}{$\begin{array}{l}\text { Contrato arrendamiento. } \\
\text { Trauma peri mortem }\end{array}$} & Y-STRS \\
\hline & & GAP & 21 & 13.311 & $\leq 18$ & & Identificación osteológica \\
\hline & & PRG & 20 & 13.312 & $\leq 21$ & & mtDNA \\
\hline \multirow{2}{*}{$18 / 09 / 1936$} & \multirow{2}{*}{$\begin{array}{l}\text { Sepultura } 38 \\
\quad \text { Fila } 4\end{array}$} & JMBA & 30 & 10.201 & $28.7(23-46)$ & \multirow{2}{*}{$\begin{array}{l}\text { Contrato arrendamiento } \\
\text { sepultura }\end{array}$} & Identificación osteológica \\
\hline & & JMM & 41 & 10.202 & $52(29-88)$ & & STRs \\
\hline 22/09/1936 & $\begin{array}{l}\text { Sepultura } 39 \\
\text { Fila } 4\end{array}$ & CMA (q) & 37 & 10.211 & $35.2(23-57)$ & $\begin{array}{l}\text { Único esqueleto femeni- } \\
\text { no. Trauma peri mortem }\end{array}$ & Identificación osteológica \\
\hline $31 / 10 / 1936$ & $\begin{array}{l}\text { Sepultura } 23 \\
\quad \text { Fila } 5\end{array}$ & SOA & 18 & 6.521 & $\leq 18$ & $\begin{array}{l}\text { Contrato arrendamiento. } \\
\text { Trauma peri mortem }\end{array}$ & Identificación osteológica \\
\hline \multirow{2}{*}{ 01/09/1936 } & \multirow{2}{*}{$\begin{array}{l}\text { Sepultura } 17 \\
\quad \text { Fila } 5\end{array}$} & ERF & 19 & 10.812 & $\leq 18$ & \multirow{2}{*}{$\begin{array}{l}\text { Contrato arrendamiento. } \\
\text { Trauma peri mortem }\end{array}$} & Y-STRs \\
\hline & & SER & 57 & 10.811 & $52(29-88)$ & & Identificación osteológica \\
\hline \multirow{7}{*}{ 10/03/1937 } & \multirow{4}{*}{$\begin{array}{l}\text { Sepultura } 65 \\
\quad \text { Fila } 8\end{array}$} & DAV & 27 & 3.181 & $<32$ & \multirow{7}{*}{$\begin{array}{l}\text { Contrato arrendamiento. } \\
\text { Trauma peri mortem }\end{array}$} & STRs \\
\hline & & JDE & 29 & 3.403 & $35.2(23-57)$ & & STRs \\
\hline & & MCE & 27 & 3.183 & $28.7(21-46)$ & & Y-STRs \\
\hline & & SCC & 42 & 3.402 & $45.6(27-66)$ & & STRs \\
\hline & \multirow{3}{*}{$\begin{array}{l}\text { Sepultura } 66 \\
\quad \text { Fila } 8\end{array}$} & AAV & 40 & 3.184 & $35.2(23-57)$ & & Y-STRs \\
\hline & & JAV & 26 & 3.401 & $35.2(23-57)$ & & Y-STRS \\
\hline & & TCO & 40 & 3.182 & $35.2(23-57)$ & & Osteológica \\
\hline
\end{tabular}

Tabla 12: Resumen de las seis identificaciones osteológicas. Todos los casos se basan en la corroboración de información relativa a la localización del enterramiento, perfil biológico básico, y a la existencia de identificaciones sustentadas con prueba genética dentro de la misma sepultura y a la existencia de contrato de arrendamiento de la sepultura. / Summary of the six osteological identifications. All cases are based on the corroboration of information related to the location of the burial and the basic biological profile, and on the existence of previous identifications supported by genetic coincidence for other skeletons of the burial or group and on the existence of a burial lease. 


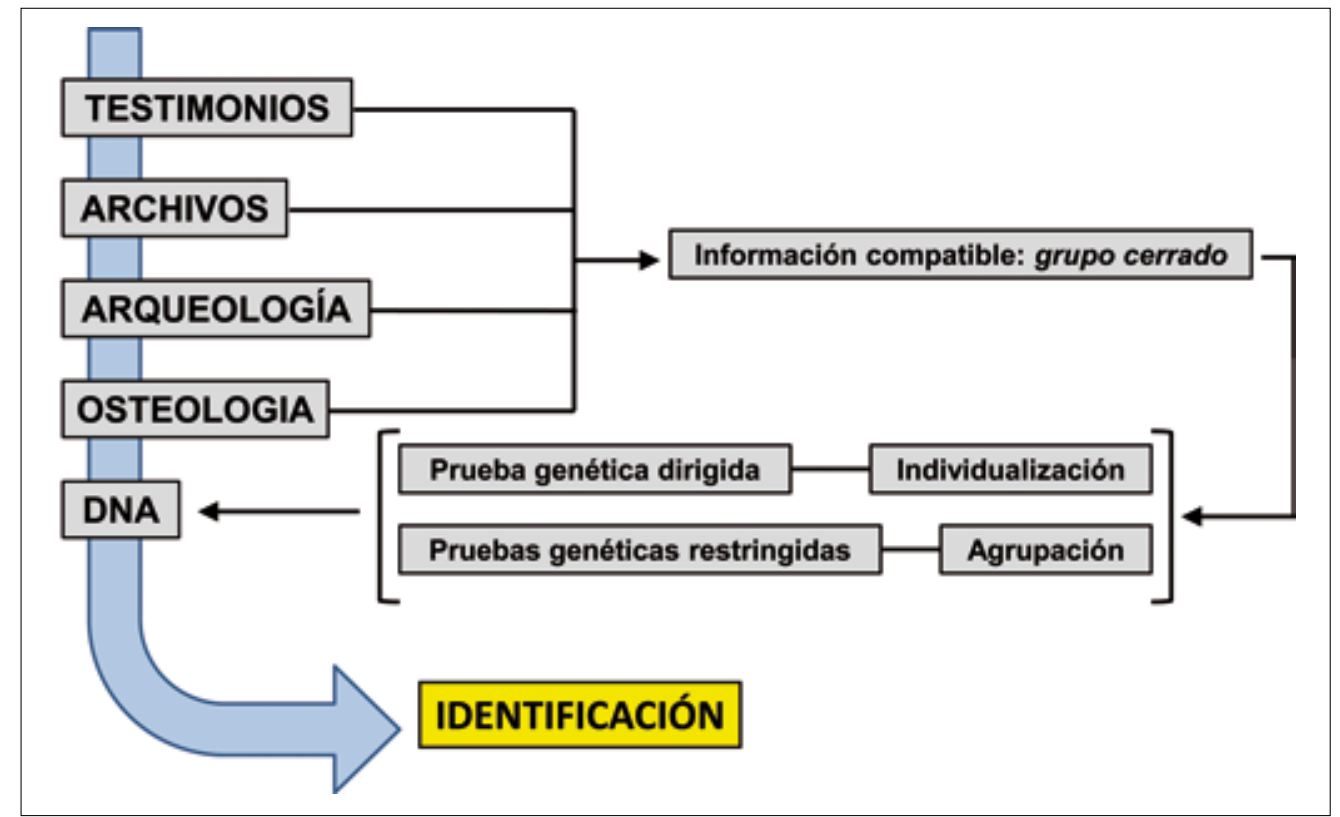

Fig.18. Esquema del proceso de identificación basado en la hipótesis de presencia de grupo cerrado. / Scheme followed to obtain an identification, based on hypothesis of closed synchronic group. et al., 2008), el proceso de identificación que hemos presentado para el caso de La Carcavilla constituye un ejemplo que se acomoda a una de las definiciones más recientes de la antropología forense (DIRKMAAT et al., 2008). En el contexto actual, esta disciplina ha sido descrita como aquella que "estudia la vida, muerte e historia post mortem de un individuo concreto tal y como se refleja básicamente en sus restos esqueléticos y en el contexto físico y forense en el cual se ha encontrado". El antropólogo forense, además de reconstruir el perfil biológico básico en el estudio de laboratorio, trata de reconstruir los eventos alrededor de la muerte valiéndose de los principios de la arqueología durante la búsqueda y recuperación de la evidencia física, y de la tafonomía, analizando los restos óseos en el contexto físico en que se encontraron. En el caso de la Carcavilla hemos visto como la dinámica cementerial, reconstruida a través de la información documental y la evidencia arqueológica y osteológica, ejerció de agente tafonómico, y su estudio ha servido de explicación a la existencia de los distintos tipos de grupos descritos (completos, parciales y ausentes). Mediante la evaluación conjunta de los datos osteológicos y genéticos sumados a esta información básica se consiguió no solo cubrir el objetivo central de la identificación, sino también reconstruir el destino de todos los represaliados enterrados en el Término $1^{\circ} \mathrm{Sec}-$ ción $3^{a}$ del Cementerio Viejo de Palencia. En este sentido, las identificaciones reflejan que, a la hora de realizar la inhumación, los cadáveres debían ser depositados de forma aleatoria, respetándose el número de cuerpos por sepultura, pero no la identidad, quedando de esta forma desordenados respecto a lo que se registraba en la documentación cementerial. Cinco años después, cuando el familiar pagaba para evitar que la fosa se reutilizara y los restos fueran trasladados al osario, que los restos permanecieran allí dependía básicamente del azar. El resultado es que varias familias de las víctimas pagaron contratos de arrendamiento con la intención de mantener las sepulturas donde estaban enterrados sus seres queridos cuando los restos de estos ya habían sido trasladados al osario.

\section{CONCLUSIÓN}

En conclusión, el proyecto de exhumación e identificación de los represaliados enterrados en La Carcavilla resultó en la exhumación de 108 esqueletos de 44 sepulturas, con un total de 57 identificados, de los cuales 51 fueron devueltos a sus familias. Las identificaciones se basaron en la corroboración y evaluación conjunta de información proveniente de diversas fuentes (testimonios, archivos, arqueología, osteología, genética), indicando la necesidad de una investigación multidisciplinar en casos de graves violaciones de derechos humanos. Además de responder a una demanda inmediata para la identificación y devolución a las familias de los restos de los represaliados, la cantidad y diversidad de la información recuperada en estas investigaciones constituye un nuevo registro de datos a disposición de futuras investigaciones históricas y legales, así como materia de reflexión en derechos humanos.

\section{AGRADECIMIENTOS}

Queremos expresar nuestro agradecimiento a las familias de Palencia por su confianza en el equipo. A Manolo Monge, Federico Lozano Ginel, los demás compañeros de equipo y voluntarios que participaron en la excavación por su dedicación al proyecto. Este trabajo está dedicado a la memoria de José Ignacio Marín Cantera, alcalde de Villaviudas, luchador por la memoria y buen amigo. 


\section{BIBLIOGRAFIA}

Avial, L., 2008. Informe Técnico de Inspección mediante Georradar en el parque de la Carcavilla (Palencia). Cóndor Georadar, Inédito.

Alt, K.W., Pichler, S., Vach, W., Klíma, B., Vlcek, E., Sedlmeier, J., 1997. Twentyfive thousand-year-old triple burial from Dolní Vestonice: an ice-age family. American Journal of Physical Anthropology 102, 123-131.

Baraybar, J.P., 2008. When DNA is not available, can we still identify people? Recomendations for best practice. Journal of Forensic Sciences 53, 533-540.

Birus, I., Marcikić, M., Lauc, D., Dzijan, S., Lauc, G., 2003. How high should paternity index be for reliable identification of war victims by DNA typing? Croatian Medical Journal 44(3), 322-6.

Barbería-Marcalain, E., Castellá-García, J., Medallo-Muñiz, J., 2009. Identification of minors in disasters. Anales de Pediatria 70(4), 392-393.

Brooks, S, Suchey, J.M., 1990. Skeletal age determination based on the OS pubis: a comparison of the Acsádi Nemeskéri and Suchey-Brooks method. Human Evolution 5(3), 227-238.

Bruzek, J., 2002. A method for visual determination of sex, using the human hip bone. American Journal of Physical Anthropology 117(2), 157-168.

Buckberry, J.L., Chamberlain, A.T., 2002. Age estimation from the auricular surface of the ilium: A revised method. American Journal of Physical Anthropology 119(3), 231-239.

Buikstra, J.E., Ubelaker, D.H., 1994. Standars for Data Collection from Human Skeletal Remains. Fayetteville (USA), Arkansas Archaeological Survey.

Cardoso, H., 2008a. Epiphyseal Union at the Innominate and Lower Limb in a Modern Portuguese Skeletal Sample, and Age Estimation in Adolescent and Young Adult Male and Female Skeletons. American Journal of Physical Anthropology 135, 161-170.

Cardoso, H. 2008b. Age Estimation of Adolescent and Young Adult Male and Female Skeletons II, Epiphyseal Union at the Upper Limb and Scapular Girdle in a Modern Portuguese Skeletal Sample. American Journal of Physical Anthropology 137, 97-105.

Cardoso, H., Ríos, L., 2010. Age Estimation from Stages of Epiphyseal Union in the Presacral Vertebrae. American Journal of Physical Anthropology 144(2), 238-47.

De Mendonça, M.C., 2000. Estimation of height from the length of long bones in a Portuguese adult population. American Journal of Physical Anthropology 112(1), 39-48.

Dirkmaat, D.C., Cabo, L.L., Ousley, S.D., Symes, S.A., 2008. New perspectives in forensic anthropology. Yearbook Physical Anthropology 51, 33-52.

Doretti, M., Snow, C., 2003. Forensic Anthropology and Human Rights: the Argentine experience. In: Steadman, D. (Ed.), Hard evidence: case studies in Forensic Anthropology, 290-310. Upper Saddle River, N J Pearson Education.

Etxeberria, F., 2004. Panorama organizativo sobre Antropología y Patología Forense en España. Algunas propuestas para el estudio de fosas con restos humanos de la Guerra Civil española de 1936. In: La memoria de los olvidados. Un debate sobre el silencio de la represión franquista, 183-219, Editorial Ámbito, Valladolid.
Etxeberria, F., 2010. La identificación y el informe pericial integrado en Antropología Forense. In: IX Curso de Patología Forense, Logroño, 19-28.

Etxeberria, F., 2012. Antropología Forense de la Guerra Civil Española. Boletín Galego de Medicina Legal e Forense, 18. Asociación Galega de Médicos Forenses.

Etxeberri, F., Herrasti, L., López, L., Albisu, C., Jiménez, J., Cardoso, S., Baeta, M., Nuñez, C., Palencia, L., Martínez, M., 2012. Exhumación, identificación y causa de muerte en Aibar-Oibar (Navarra). Munibe Antroplogia-Arkeologia 63, 367-377.

Ferrándiz, F., 2014. El pasado bajo tierra. Exhumaciones contemporáneas de la Guerra Civil. Barcelona, Anthropos.

García Colmenares, P., 2012. Víctimas de la guerra civil en la provincia de Palencia (1936-1945). ARMH Palencia.

García-Rubio, A., Martínez, B., Ríos, L., Etxeberría, F., 2009. Informe del estudio osteológico de los restos exhumados en el Parque de la Carcavilla, Palencia. Ministerio de la Presidencia, Sociedad de Ciencias Aranzadi y UAM. Informe inédito.

García-Rubio, A., Iglesias, J., 2014. Estudio de los restos exhumados en la fosa de "El Valle". In: Olmedo, A. (Coord), Arroyo de San Serván en el contexto de la II República y la represión franquista. Diputación de Badajoz y Ayuntamiento de San Serván.

García-Rubio, A., Jiménez, J., Martínez, B., Coch, C., Llidó, S., Herrasti, L., Etxeberría, F., Ríos, L., 2016. Arqueología de la represión franquista. Exhumaciones en cementerios: el ejemplo de Palencia. In: Morín, J., Pérez-Juez, A. (Eds), Arqueología de la Guerra Civil Española. British Archaeological Reports. En prensa.

Garvin, H.M., 2008. Ossification of laryngeal structures as indicators of age. Journal Forensic Sciences 53(5), 1023-1027.

Gornik, I., Marcikic, M., Kubat, M., Primorac, D., Lauc, G., 2002. The identification of war victims by reverse paternity is associated with significant risks of false inclusion. International Journal Legal Medicine 116(5), 255-7.

Guijo, J.M., Carrasco, I., Romero, C., Vera, E., 2013. Arqueología y muerte violenta: consideraciones en torno a una exhumación de represaliados de 1936 en el Cementerio de la Puebla de Cazalla (Sevilla). Antiquitas 25, 275-292.

Herrasti, L., Etxeberría, F., Martínez de Pancorbo, M., Cardoso, S. 2012. Exhumación y análisis de los restos de la fosa de Agreda, Soria. Boletín Galego de Medicina Legal e Forense 18, 55-70.

Iscan, M.Y., Loth, S.R., Wright, R.K., 1984. Age estimation from the rib by phase-analysis White males. Journal Forensic Sciences 29(4), 1094-1104.

Jiménez, J.M., 2009. Informe preliminar de la prospección arqueológica en el Parque de la Carcavilla, Palencia. Ministerio de la Presidencia, Sociedad de Ciencias Aranzadi. Informe inédito.

Kimmerle, E.H., Jantz, R.L., Konigsberg, L.W., Baraybar, J.P., 2008. Skeletal estimation and identification in American and East European populations, Journal Forensic Science 53:524-532.

Komar, D., Lathrop, S., 2006. Frequencies of morphological characteristics in two contemporary forensic collections: Implications for identification. Journal Forensic Sciences 51(5), 974-978.

Langley-Shirley, N., Jantz, R.L., 2010. A Bayesian Approach to Age Estimation in Modern Americans from the Clavicle. Journal of Forensic Sciences 55, 571-583. 
Lozano, F., 2009 Método de confección del plano correspondiente a la sección tercera del primer término del cementerio viejo de Palencia. In: García-Rubio, A. (Coord), Informe del estudio osteológico de los restos exhumados en el Parque de la Carcavilla, Palencia, Ministerio de la Presidencia, Sociedad de Ciencias Aranzadi y UAM. Informe inédito.

Malgosa, A., Armentano, N., Galtés, I., Jordana, X., Subirana, M., Gassiot, E., Lalueza, C., Solé, Q., 2010. La antropología forense al servicio de la justicia y la historia: las fosas de la Guerra Civil. Cuadernos de Medicina Forense 16(1-2), 65-79.

Meijerman, L., Maat, G.J., Schulz, R., Schmeling, A., 2007. Variables affecting the probability of complete fusion of the medial clavicular epiphysis. International Journal of Legal Medicine 121(6), 463-468.

Mezquida Fernández, M., 2017. Excavaciones y exhumaciones de fosas de la Guerra Civil y del Franquismo en el País Valenciano. La Linde 8. En prensa.

Muñoz-Encinar, L., Ayán, X., López, A., 2013. De la ocultación de las fosas a las exhumaciones. La represión franquista en el entorno del campo de concentración de Castuera (Badajoz). INCIPIT, CSIC, AMECADEC, Santiago.

Murail, P., Bruzek, J., Houët, F., Cunha, E., 2005. DSP: a tool for probabilistic sex diagnosis using worldwide variability in hip-bone measurements. Bulletins et Mémoires de la Société d'Anthropologie de Paris 17(3-4), 167-176.

Obafunwa, J.O., Ogunbanjo, V.O., Ogunbanjo, O.B., Soyemi, S.S., Faduyile, F.A., 2015. Forensic odontological observations in the victims of DANA air crash. The Pan African Medical Journal 20, 96.

Phenice, T.W., 1969. A newly developed visual methods of sexing the os pubis. American Journal of Physical Anthropology 30, 297-301.

Polo, M., Cruz, E., García, E., 2010. Arqueología y Antropología Forense de la Represión Franquista en el Territorio de la Agrupación Guerrillera de Levante y Aragón (1947-1948). Ebre 38(4), 203-23.

Prada, E., Etxeberria, F., Herrasti, L., Vidal, J., Macias, S., Pastor, F., 2003. Antropología del pasado reciente: una fosa común de la Guerra Civil española en Priaranza del Bierzo (León). In: Aluja, M.P., Malgosa, A., Nogues, R.M. (Coord.), Antropología y Biodiversidad Volumen I, 431-446. Ediciones Bellaterra, Barcelona.

Raszeja, S., Chroscielewski, E., 1994. Medicolegal reconstruction of the Katyn forest massacre. Forensic Science International 68, 1-6.

Raxter, M.H., Auerbach, B.M., Ruff, C.B., 2006. Revision of the fully technique for estimating statures. American Journal of Physical Anthropology 130(3), 374-384.

Raxter, M.H., Ruff, C.B., Auerbach, B.M., 2007. Technical note: Revised fully stature estimation technique. American Journal of Physical Anthropology 133(2), 817-818.

Ríos, L., 2012. Identificación en fosas comunes de la Guerra Civil: limitaciones y posibilidades a partir del caso de Burgos. Boletín Galego de Medicina Legal e Forense 18, 125-142.

Ríos, L., Martínez, B., García-Rubio, A., Jiménez, J., 2009. Muertes en cautiverio en el primer Franquismo: Exhumación del cementerio de Valdenoceda (1938-1943). Complutum 19(2), 139-160.

Ríos, L., Casado, J.I., Puente, J., 2010. Identification process in mass graves from the Spanish Civil War I. Forensic Science International 199(1-3), 27-36.
Ríos, L., García-Rubio, A., Martínez, B., Alonso, A., Puente, J., 2012. Identification process in mass graves from the Spanish Civil War II. Forensic Science International 219, 4-9.

Ríos, L., Martínez, B., García-Rubio, A., Herrasti, L., Etxeberria, F., 2014 Marks of autopsy and identification of victims of human rights violations exhumed from cemeteries: the case of the Spanish Civil War (1936-1939). International Journal of Legal Medicine 128, 889

Ríos, L., García-Rubio, A., Martínez, B., Herrasti, L., Etxeberria, F., 2014. Patterns of perimortem trauma in skeletons recovered from mass graves from the Spanish Civil War (1936-1939). In: Smith, M.J., Knüsel, C. (Eds.), The Routledge Handbook of the Bioarchaeology of Human Conflict, 621-640. Routledge, Oxford.

Ríos, L., Etxeberria, F., 2016. The Spanish Civil War Forensic Labyrinth. In: Ferran, O.,y Hilbink, L. (Eds.), Legacies of Violence in Contemporary Spain: Exhuming the Past, Understanding the Present, 174-198. Routledge Studies in Modern European History.

Ríos, L., Mata-Escolano, F., Blanco, E., Llidó, S., Bastir, M., Sanchís-Gimeno, J.A., 2017. Acute headache attributed to whiplash in arcuate foramen and non-arcuate foramen subjects. European Spine Journal 26(4), 1262-1265.

Saunders, S.R., Popovich, F., 1978. Family study of 2 skeletal variants - Atlas bridging and clinoid bridging. American Journal Physical Anthropology 49(2), 193-203.

Schotsmans, E., García-Rubio, A., Edwards, H., Munshi, T., WiIson, A., Ríos, L., 2017. Analyzing and Interpreting Lime Burials from the Spanish Civil War (1936-1939): A Case Study from La Carcavilla Cemetery. Journal of Forensic Sciences 62(2), 498-510.

Scott, G.R., Irish, J.D., 2017. Human tooth Crown and root morphology. The Arizona State University Dental Anthropology System. Cambridge University Press, Cambridge.

Silva, E., 2006. Las fosas de Franco. Temas de Hoy, Madrid.

Snodgrass, J.J., 2004. Sex differences and aging of the vertebral column. Journal Forensic Sciences 49(3), 458-463.

Steadman, D., Haglund, W., 2005. The scope of anthropological contributions to human rights investigations. Journal of Forensic Science 50(1): 23-30.

Webb, P.A., Suchey, J.M., 1985. Epiphyseal union of the anterior iliac crest and medial clavicle in a modern multiracial sample of American males and females. American Journal Physical Anthropology 68, 457-466. 
